\title{
GRAd-COV2, a gorilla adenovirus-based candidate vaccine against COVID-19, is safe and immunogenic in younger and older adults
}

\begin{abstract}
Simone Lanini $^{1 \dagger}$, Stefania Capone ${ }^{2 \dagger}$, Andrea Antinori ${ }^{1}$, Stefano Milleri $^{3 \dagger}$, Emanuele Nicastri ${ }^{1}$, Roberto Camerini ${ }^{2}$, Chiara Agrati' ${ }^{1}$, Concetta Castilletti', Federica Mori ${ }^{2}$, Alessandra Sacchi', Giulia Matusali', Roberta Gagliardini', Virginia Ammendola ${ }^{2}$, Eleonora Cimini ${ }^{1}$, Fabiana Graziolii ${ }^{2}$, Laura Scorzolini ${ }^{1}$, Federico Napolitano ${ }^{2}$, Maria $M$. Plazzi $^{1}$, Marco Soriani $^{2}$, Aldo De Luca ${ }^{1}$, Simone Battella $^{2}$, Andrea Sommella ${ }^{2}$, Alessandra M. Contino ${ }^{2}$, Federica Barra $^{2}$, Michela Gentile ${ }^{2}$, Angelo Raggioli ${ }^{2}$, Yufang Shi ${ }^{4,5}$, Enrico Girardi', Markus Maeurer ${ }^{6,7}$, Maria $R$. Capobianchi $^{1,8}$, Francesco Vaia ${ }^{1}$, Mauro Piacentini ${ }^{9}$, Guido Kroemer ${ }^{10,11,12,13}$, Alessandra Vitelli ${ }^{2}$, Stefano Colloca $^{2}$, Antonella Folgori ${ }^{2+*}$, Giuseppe Ippolito ${ }^{1+*}$
\end{abstract}

${ }^{1}$ Istituto Nazionale per Le Malattie Infettive Lazzaro Spallanzani IRCCS; 00149, Rome, Italy. ${ }^{2}$ ReiThera Srl; 00128, Rome, Italy. ${ }^{3}$ Centro Ricerche Cliniche di Verona srl; 37134 Verona, Italy. ${ }^{4}$ First Affiliated Hospital of Soochow University; Suzhou, 215008, Jiangsu, China. ${ }^{5}$ Shanghai Institute of Nutrition and Health, Shanghai Institutes for Biological Sciences, Chinese Academy of Sciences; 200061, Shanghai, China. ${ }^{6}$ Division of Immunotherapy, ImmunoSurgery, Champalimaud Foundation; 1400-038, Lisboa, Portugal. ${ }^{7}$ I Medical Clinic, University of Mainz; 55122, Mainz, Germany. ${ }^{8}$ Saint Camillus International University of Health Sciences, 00131, Rome, Italy ${ }^{9}$ Department of Biology, University of Rome "Tor Vergata; 00133, Rome, Italy. ${ }^{10}$ Centre de Recherche des Cordeliers, Equipe labellisée par la Ligue contre le cancer, Université de Paris, Sorbonne Université, Inserm U1138, Institut Universitaire de France, 75006, Paris, France. ${ }^{11}$ Metabolomics and Cell Biology Platforms, Institut Gustave Roussy; 94805, Villejuif, France. ${ }^{12}$ Pôle de Biologie, Hôpital Européen Georges Pompidou; 75015, Paris, France. ${ }^{13}$ Department of Women's and Children's Health, Karolinska University Hospital, 17164, Stockholm, Sweden

†These authors contributed equally to this work

$\ddagger$ on behalf of the GRAd study group

*Corresponding author. Email: antonella.folgori@reithera.com

Safe and effective vaccines against coronavirus disease 2019 (COVID-19) are essential for ending the ongoing pandemic. Although impressive progress has been made with several COVID-19 vaccines already approved, it is clear that those developed so far cannot meet the global vaccine demand alone. We describe a COVID-19 vaccine based on a replication-defective gorilla adenovirus expressing the stabilized pre-fusion SARS-CoV-2 spike protein, named GRAd-COV2. We assessed the safety and immunogenicity of a singledose regimen of this vaccine in healthy younger and older adults to select the appropriate dose for each age group. To this purpose, a phase 1, dose-escalation, open-label trial was conducted including 90 healthy participants, (45 aged 18 to 55 years and 45 aged 65 to 85 years), who received a single intramuscular administration of GRAd-COV2 at three escalating doses. Local and systemic adverse reactions were mostly mild or moderate and of short duration, and no serious adverse events were reported. Four weeks after vaccination, seroconversion to spike protein and receptor binding domain was achieved in 43 of 44 young volunteers and in $\mathbf{4 5}$ of $\mathbf{4 5}$ older participants. Consistently, neutralizing antibodies were detected in $\mathbf{4 2}$ of 44 younger age and $\mathbf{4 5}$ of $\mathbf{4 5}$ older age volunteers. In addition, GRAd-COV2 induced a robust and Th1skewed T cell response against the spike protein in 89 of 90 participants from both age groups. Overall, the safety and immunogenicity data from the phase 1 trial support further development of this vaccine.

\section{INTRODUCTION}

The coronavirus disease 2019 (COVID-19) pandemic is one of the most major international public health emergencies that have occurred over the last century. COVID-19 is caused by severe acute respiratory syndrome coronavirus 2 (SARSCoV-2), which emerged in the People Republic of China at the end of 2019. Since its start, the COVID-19 pandemic has already caused hundreds of millions of infections with several million fatalities worldwide. This unprecedented global health emergency has boosted international efforts to develop a vaccine targeting SARS-CoV-2. A multitude of innovative platforms have been used, including genetic vaccines based on mRNA, DNA and viral vectors. As of September 2021, there are as many as 315 vaccine candidates still in development. One hundred and ninety-four are in preclinical development and 121 in clinical development, of which 22 are either authorized for emergency use or approved by different countries (1). However, with most of the world's population 
yet to be vaccinated and the potential need for booster doses, the COVID-19 vaccines rolled out so far cannot meet the global vaccine demand. Thus, there is an urgent need to develop additional safe and effective vaccines to be included in worldwide vaccination campaigns.

Here, we developed GRAd-COV2, a vaccine candidate based on an adenoviral vector derived from a group C Gorilla adenovirus that is made replication defective by deleting the E1 genomic region. To increase cloning space and productivity, the vector is also deleted of the E3 genomic region, and includes a modification of the E4 region (2). The GRAd-COV2 vaccine encodes for a full-length SARS-COV-2 spike (S) protein. The spike protein is the primary vaccine target for most COVID-19 vaccines, as it is critical for viral cell entry through the human angiotensin converting enzyme 2 (ACE2) receptor (3). The spike gene that was cloned into GRAd-COV2 contains mutations that stabilize the spike protein expressed in the host cell in a pre-fusion conformation $(4,5)$. The GRAd vector was selected based on its immunogenicity and manufacturability profile, in addition to the low frequency of anti-GRAd neutralizing antibodies in human serum samples as compared with human adenovirus type 5 (2). We recently reported that a single dose of GRAd-COV2 elicited strong immune responses, both humoral and cellular, in mice and rhesus macaques (2). These preclinical data supported the start of a first-in-human, dose escalation, phase 1 clinical trial in healthy younger and older adults to evaluate the safety and immunogenicity of GRAd-COV2. Here we report the trial interim analysis results up to 4 weeks after vaccination.

\section{RESULTS}

\section{Volunteer screening and selection}

Between August 11 and September 20, 2020, 181 potential volunteers were evaluated for eligibility. Volunteers were screened in excess for speeding up enrollment and to comply with a strict staggering enrollment scheme. Of the 181 participants screened, 91 (45 in the younger adult cohort aged 18 to 55 and 46 in the older adult cohort, aged 65 to 85 ) were vaccinated. Fifty-five volunteers (30 in younger age cohort and 25 in the older age cohort) were excluded as they did not meet inclusion criteria and 35 (25 younger age cohort and 10 in the older age cohort) were not vaccinated because time from screening visit to vaccination visit exceeded the window allowed per protocol. Median age, gender distribution, and other characteristics were well balanced within study arms both in the younger adult (Fig. 1A) and in the older adult (Fig. 1B) cohorts.

One vaccinated arm 1 volunteer had detectable anti-nucleoprotein ( $\mathrm{N}$ protein) and spike protein IgG starting at week 1 after vaccination. As this finding suggested a natural (asymptomatic) infection with SARS-CoV-2, we excluded this individual from the immunogenicity analysis. One participant who was vaccinated in arm 4 was found to be positive at baseline for anti-spike protein IgG by chemiluminescent immunoassay (CLIA), the primary serology assay per the study protocol for the evaluation of vaccine-induced spike proteinspecific antibody responses. The volunteer did not develop antibodies specific to $\mathrm{N}$ protein, and tested negative by a SARS-CoV-2 virus-based immunofluorescence assay, suggesting a non-specific reactivity by the CLIA that made the vaccine-induced spike antibody response not reliably evaluable. Thus the volunteer was replaced with a subsequent one, and was included in the safety analysis but excluded from the immunogenicity assessment. Moreover, 3 additional volunteers (arms 2, 3, and 5) were excluded from interferon (IFN)- $\curlyvee$ enzyme-linked immunospot (ELISpot) analysis due to spontaneous IFN- $\curlyvee$ production above acceptability range (Fig. 1).

\section{Vaccine safety}

A single intramuscular administration of GRAd-COV2 was well-tolerated at all doses and in both cohorts (Fig. 2). Most adverse events (AEs) occurred in the first 2 days after vaccination and were short-lived (median time to resolution 1 day, IQR less than 1 day to 2 days). Overall, we observed 328 AEs of any grade; of those, 255 were considered to be related to vaccination. In the younger age cohort, we observed 143 solicited AEs (118 mild and 25 moderate) and 8 unsolicited AEs (4 mild and 4 moderate). Among younger volunteers, injection site pain (34), fatigue (30), headache (26) and fever (21) where the most common AEs.

In the older age cohort, we observed 104 solicited AEs (79 mild, 13 moderate and 2 severe) and 10 unsolicited AEs (5 mild, 3 moderate and 2 severe). Among older volunteers, chills (18), fever (17), fatigue (15), myalgias (14) and headache (13) where the most common AEs.

Twenty-four volunteers (26\%; 7 younger and 17 older) reported no AEs, 44 volunteers (48\%; 23 younger and 21 older) reported at least one mild $\mathrm{AE}$ and 21 volunteers $(48 \% ; 15$ younger and 6 older) reported at least one moderate AE. Two volunteers ( $2 \%$; both older age volunteers) reported at least one severe AE. One of these participants had received high GRAd-COV2 dose and reported fever (moderate) with severe fatigue, cough and chills starting a few hours after vaccination and resolving within few days. The second volunteer was in the intermediate dose group and presented with severe neutropenia without symptoms on day 2 after vaccination (total neutrophil count of 780 cells $/ \mathrm{mm}^{3}$ ); this individual's neutrophil count was within normal range by day 7 (total neutrophil counts 1620 cells $/ \mathrm{mm}^{3}$ ).

No serious AE was reported, and no pre-specified trialhalting rules were met. Nineteen volunteers (15 younger and 4 older) received antipyretics to control AEs. One older age volunteer received inhalator steroids for a cough that started the day after the vaccination that resolved in 9 days. Overall, no clinically meaningful blood count changes were observed. A transient reduction of neutrophils with concomitant 
increase in monocytes was detected at day 2 in the majority of volunteers in all age and vaccine dose groups that mostly reverted to pre-dose values by week 1 (fig. S1). Other hematological parameters were mostly unaffected (fig. S1).

Binding antibodies to SARS-CoV-2 spike protein were elicited following vaccination.

Antibody responses to GRAd-COV2 vaccination was primarily monitored by a clinically validated CLIA, revealing similar kinetics of anti-spike protein IgG induction in all study groups (Fig. 3A and table S1). Seroconversion for spike protein occurred at week 2 , when anti-spike protein IgG became detectable in 23 (52\%) out of 44 of the younger volunteers and in 15 (33\%) out of 45 of the older age participants. At week 4 after vaccination, high concentrations of anti-spike protein IgG were measurable in 40 (91.0\%) out of the 44 analyzed younger and in $42(93.3 \%)$ out of the 45 older age volunteers. In the younger age cohort, three volunteers (one in the intermediate dose arm and two in the high dose arm) showed a weak increase of anti-spike protein IgG (10.8 Arbitrary Units $[\mathrm{AU}] / \mathrm{ml}, 11.5 \mathrm{AU} / \mathrm{ml}$, and $12.8 \mathrm{AU} / \mathrm{ml}$, respectively), that were below the diagnostic cutoff applied in the clinical practice $(15.0 \mathrm{AU} / \mathrm{ml})$. Only one volunteer in the low dose arm showed anti-spike protein IgG below the assay limit of detection (LOD; <3.8 AU/ml). Also in the older age cohort, three volunteers (one in low dose, one in intermediate dose, one in high dose arm) showed a weak increase of anti-spike protein IgG (5.0 AU/ml, 8.5 AU/ml and 9.7 AU/ml respectively) that were below the diagnostic cutoff.

Antibodies measured by CLIA did not show a dose response relationship in the younger adult cohort (IgG concentrations at week 4 were 59.5, 60.6 and $61.8 \mathrm{AU} / \mathrm{ml}$ for low dose, intermediate dose, and high dose, respectively, $\mathrm{P}=0.742$ ). A dose response trend was also not observed in the older age cohort (IgG concentrations at week 4 were 31.8, 41.0 and 56.3 $\mathrm{AU} / \mathrm{ml}$ for low dose, intermediate dose, and high dose, respectively, $\mathrm{P}=0.315)$. However, despite the absence of a dose-response within the cohort, we observed that low and intermediate vaccine doses were associated with significantly lower IgG responses in older age volunteers (low dose arms median IgG was 59.4 in younger and 31.8 in older adults, $\mathrm{P}=0.011$; intermediate dose arms median IgG was 60.6 in younger and 41.0 in older adults, $\mathrm{P}=0.011$ ). High vaccine dose elicited similar concentrations of IgG among the two age cohorts (high dose arms median IgG was 61.8 in younger and 56.3 in older adults, $\mathrm{P}=0.917)$.

An enzyme linked immunosorbent assay (ELISA) showed that $89(98.8 \%)$ out of 90 volunteers developed detectable anti-spike protein IgG, including both antibodies against the whole spike protein and against the receptor binding domain (RBD) at 4 weeks after vaccination (Fig. 3B and $\mathrm{C}$ and table S1). None of the study volunteers showed seroconversion to $\mathrm{N}$ protein during the 4 weeks following vaccination, suggesting that no SARS-CoV-2 infection occurred.

Neutralizing antibodies against SARS-CoV-2 were elicited by GRAd-COV2 vaccination.

Neutralizing antibodies to SARS-CoV-2 were assessed by two different in vitro assays, both using SARS-CoV-2 live virus. No SARS-CoV-2 neutralizing antibodies were detected at baseline by a microneutralization assay (MNA). Four weeks after vaccination, serum neutralizing antibodies were detected in 25 of 44 (56.8\%) younger volunteers and in 33 of 45 (73.3\%) older volunteers (Fig. 3D). Anti-SARS-CoV-2 neutralizing antibodies were below the limit of detection in 8,5 , and 6 younger, and in 3,5 , and 4 older volunteers in the low dose, intermediate dose, and high dose arms, respectively.

A more sensitive plaque reduction neutralization test (PRNT) revealed SARS-CoV-2 neutralizing antibodies in 42 of 44 (92.5\%) younger and in 45 of 45 (100\%) older volunteers (Fig. 3E). The two younger volunteers with undetectable neutralizing antibody were in the lose dose arm. In the older adult cohort, we observed a significant dose-dependent increase in the concentration of neutralizing antibodies (median $\mathrm{PRNT}_{50}$ titer 38.0, 35.0 and 61.0 in the low dose, intermediate dose, and high dose arms respectively; $\mathrm{P}=0.048$ ). A dose-response trend was not observed across the arms in the younger adult cohort (median $\mathrm{PRNT}_{50}$ titer 23.5, 31.0 and 41.0 in the low dose, intermediate dose, and high dose arms respectively; $\mathrm{P}=0.197$ ). Across all arms, titers of binding and neutralizing antibodies elicited by GRAd-COV2 vaccination were in the range of those measured in convalescent individuals who recovered from mild cases of COVID-19 (Fig. 3A to D and table S1). We calculated the ratio between geometric mean antibody titers (GMT) in volunteers receiving intermediate or high GRAd-COV2 dose and GMT titers of convalescent COVID-19 patients of any severity. The ratios ranged between 0.7 and 1.2 for spike protein and RBD binding antibodies by ELISA, and was 0.76 for neutralizing antibodies based on $\mathrm{PRNT}_{50}$ values (table $\mathrm{S} 2$ ). These ratios are similar to those reported for other Ad-based vaccines whose clinical efficacy has been demonstrated $(6,7)$.

According to a correlation matrix computed on main immunological readouts of this study (fig. S2), a strong positive correlation was observed among all serological tests (neutralization, CLIA, anti-spike protein ELISA, and anti-RBD ELISA). Correlation was strongest amongst assays detecting binding antibodies (CLIA and ELISA to spike protein and $\mathrm{RBD}, \mathrm{r}$ values between 0.89 and 0.94 , all $\mathrm{P}=<0.0001$ ), and within the two neutralization assays $(\mathrm{r}=0.8, \mathrm{P}=<0.0001)$. Correlation was significant but less strong within binding and neutralizing assays ( $\mathrm{r}$ between 0.5 and 0.66 , all $\mathrm{P}=<0.0001$ ).

$T$ cell responses were induced by GRAd-COV2 vaccination.

A quantitative IFN- $\curlyvee$ ELISpot assay was used to assess T cell response on fresh peripheral blood mononuclear cells 
(PBMCs) isolated from volunteers in both cohorts at week 2 after vaccination. GRAd-COV2 administration at all three doses induced potent spike protein-specific IFN- $\gamma$ producing $\mathrm{T}$ cell response in both cohorts (Fig. $4 \mathrm{~A}$ and table $\mathrm{S} 1$ ). Individual responses ranged between 87 and $10560 \mathrm{IFN}-\gamma$ spot forming cells (SFC) per million PBMCs in younger adults and between 283 and 18877 in older individuals. Notably, 80\% of individuals evaluated across the two age cohorts showed a response above $1000 \mathrm{SFC}$ per million PBMCs. Only one volunteer in arm 1 did not show a detectable spike protein-specific $\mathrm{T}$ cell response, but still had measurable antibodies to spike protein and RBD (ELISA titer of 1494 and 721, respectively).

A similar $\mathrm{T}$ cell response was observed in the younger cohort across all three doses of vaccine (median response 1162, 2857 and 2272 SFC per million PBMCs in the low dose, intermediate dose, and high dose arms, respectively; $\mathrm{P}=0.154$ ). Likewise, all three doses elicited a similar $\mathrm{T}$ cell response in the older cohort (median response 1917, 2262 and 3142 SFC per million PBMCs in the low dose, intermediate dose, and high dose arms, respectively, $\mathrm{P}=0.206$ ). Moreover, we did not observe differences between the younger and older study arms receiving the same vaccine dose (P-values were 0.116 , 0984 and 0.152 for low dose, intermediate dose, and high dose, respectively).

$\mathrm{T}$ cell response induced by vaccination was directed to multiple epitopes, as most of the volunteers in both cohorts had a detectable response against all four spike peptide pools analyzed (fig. S3). Moreover, we found that all regions of the spike protein had a similar degree of immunogenicity in both age cohorts (Fig. 4B). Spike protein-specific T cell response was generally higher in GRAd-COV2 vaccinated individuals than in SARS-CoV-2 convalescent controls who were sampled one to two months after symptoms onset (Fig. 4A). Additionally, $\mathrm{T}$ cell immunity moderately correlated with the serological assays ( $r=0.38$ to $0.47, \mathrm{P}=0.0003$ to $<0.0001$ ), suggesting that GRAd-COV2 vaccination induced coordinated antibody and $\mathrm{T}$ cell responses to the encoded spike protein (fig. S2).

$\mathrm{T}$ cell kinetics were analyzed using cryopreserved PBMCs (fig. S4). Interestingly, the amount of baseline T cells crossrecognizing SARS-CoV-2 spike peptides, most likely memory $\mathrm{T}$ cells derived from past seasonal coronaviruses infections, increased with age. After GRAd-COV2 vaccination, T cell responses were expanded between a median of 9 and 15 -fold in younger age volunteers, whereas the fold expansion was clear but more limited in older age arms (median 3 to 4 -fold). The peak varied between week 2 and week 4 in individual volunteers, but overall, the $\mathrm{T}$ cell response was stable in the first month post vaccination.

Intracellular staining (ICS) for cytokine production and flow cytometry analysis revealed that vaccine-induced responses involved both spike protein-specific CD4 and CD8 T lymphocytes in younger (Fig. 4C and D) and older volunteers (Fig. 4E and F) with higher frequencies of CD4 $\mathrm{T}$ cells relative to CD8 T cells. Importantly, among GRAd-COV2 vaccine-induced spike protein-specific $\mathrm{CD} 4, \mathrm{IFN}-\gamma$ production was more prominent than interleukin (IL)-4 and IL-17 in both age cohorts, indicating that the vaccine induced a predominantly T helper 1 (Th1) response.

\section{Anti-vector antibodies were observed at baseline in a subset of individuals, and expanded by GRAd-COV2 vaccination.}

GRAd neutralization was not set as a screening or a randomization parameter, but was assessed as an exploratory endpoint at baseline and 4 weeks after vaccination. Out of 90 volunteers, we measured neutralization titers $>200$, a value above which an impact on vaccine immunogenicity has been reported, in only 10 volunteers (11\%). As expected, vaccination with GRAd-COV2 induced or boosted anti-vector immunity in most volunteers (Fig. 5A), with no differences attributable to vaccine dose or age.

To assess the impact of anti-GRAd immunity, pooled immunogenicity data at peak post vaccination ( $T$ cell responses or binding and neutralizing antibody responses) were stratified according to the baseline GRAd neutralizing titers (Fig. $5 \mathrm{~B}$ to $\mathrm{G}$ ). Reduced spike protein binding antibody response to the vaccine antigen was noted in volunteers with GRAd nAb $>200$ at baseline, with significantly lower IgG titers as measured by ELISA $(\mathrm{P}=0.018$ on full length spike protein and $\mathrm{P}=0.0145$ on $\mathrm{RBD}$ ). Conversely, vaccine-induced immune responses in individuals with GRAd neutralizing antibody titers in the 18 to 200 range at baseline were undistinguishable or similar to those of volunteers with no anti-vector immunity. Finally, antibody responses to spike and RBD, as measured by ELISA, inversely correlated with anti-vector antibody titers at baseline (fig. S2, $\mathrm{r}=-0.24, \mathrm{P}=0.026$ for spike protein, and $\mathrm{r}=-0.24, \mathrm{P}=0.024$ for $\mathrm{RBD}$ ).

\section{GRAd-COV2-induced immunity is not abrogated} against SARS-CoV-2 variants.

SARS-CoV-2 variants emerged soon after pandemic's onset, and assessing the degree of cross-reactivity of vaccine-induced humoral and cellular immune responses to spike proteins from the most relevant variants is of importance. A subset of 12 serum samples were evaluated at 4 weeks after vaccination for their ability to neutralize SARS-CoV-2 variants of concern (VOCs), lineage alpha (B.1.1.7) and gamma (P.1), and compared to the neutralization titers obtained using the reference strain (WA1/2020). Similar neutralization titers were observed when comparing the reference WA1/2020 and alpha, whereas a significantly lower titer (median two-fold) was detected against the gamma variant (Fig. $6 \mathrm{~A}, \mathrm{P}=0.04)$. In addition, cryopreserved PBMCs from the same volunteers were analyzed by ELISpot assay using different peptides pools spanning the spike antigens of the 
WA1/2020 and of the indicated VOCs (Fig. 6B). The results showed a robust $\mathrm{T}$ cell response against the reference strain in all the 12 samples analyzed, and $\mathrm{T}$ cell responses of similar strength were observed in response to alpha, beta, gamma, and epsilon variant peptide pools.

\section{DISCUSSION}

Here we report first-in-human data on the safety and immunogenicity of a single administration of GRAd-COV2 given at different doses in healthy younger adults aged 18 to 55 and in healthy older adults aged 65 to 85 years. GRAd-COV2 is a COVID-19 candidate vaccine based on a replication-defective gorilla adenovirus vector. Our analyses provide evidence that GRAd-COV2 is well-tolerated in both younger and older age cohorts at all three doses assessed. Most of the observed adverse events were short-lived and mild or moderate in intensity. Only two volunteers reported at least one severe adverse event and none reported serious adverse events. Solicited adverse events were less common in older age volunteers, similarly to what described for other COVID-19 vaccines (8-10). In general, the adverse event profile did not differ from those reported in published work for other vector-based vaccines (10-15) although they were milder than those reported for mRNA formulated in lipid nanoparticles and for adjuvanted vaccines $(8,16,17)$.

The vaccine was immunogenic at all doses, inducing seroconversion in the majority of participants of both age groups. Onset of immune responses was rapid with $\mathrm{T}$ cell responses already detectable 14 days after vaccination and antibodies titers increasing to day 28. We used two assays to measure neutralizing antibodies against live SARS-CoV2 in vaccinated volunteers, which exploit different virus strains and readouts. A microneutralization assay based on cytopathic effect (CPE) assessment provided evidence that $65 \%$ of the volunteers had measurable $\mathrm{MNA}_{90}$ titers, whereas a more sensitive plaque reduction assay showed $\mathrm{PRNT}_{50}$ titers in $98 \%$ of vaccinated volunteers. In general, titers of neutralizing antibodies to SARSCoV-2 were lower than those reported in studies of vaccines based on mRNA $(16,18,19)$ and possibly on other viral vectors like Ad26 and ChAdOx1 (10, 12). However, the lack of standards and the use of different assays complicate the comparison between different COVID-19 vaccines that are currently in use or in development. A comparison with convalescent serum panels stratified according to COVID-19 severity of the donors, showed that the GRAd-COV2 vaccine elicited SARSCoV-2 binding and neutralizing antibody titers similar to non-hospitalized people who had recovered from symptomatic COVID-19.

According to recent publications $(6,7)$, the GMT ratio of binding and neutralizing antibodies induced in vaccinated individuals and in COVID-19 convalescent patients may be predictive of vaccine efficacy. This ratio has been proposed as a surrogate correlate of protection, allowing normalization of immunogenicity data against convalescent patients for any vaccine regardless of the specific assay adopted in each trial to generate the data. The calculated ratio for binding and neutralizing antibodies induced in GRAd-COV2 vaccinated individuals is in the range of that reported for other adenoviral vector vaccines, like ChAdOx1-nCoV-19 and Ad26.COV2.S.

A single administration of GRAd-COV2 elicits a robust and Th1-skewed immune response within 2 weeks that is broadly directed to multiple spike protein epitopes, similar to that induced by a single dose of other vectored COVID-19 vaccines such as ChAdOx1 nCoV-19 (12), Ad5-nCoV $(14,15)$ and Ad26.COV2.S (10), and by two doses of mRNA-1273 (16, 18). Importantly, a robust $\mathrm{T}$ cell response, such as that elicited by GRAd-COV2, may determine the duration of anti-COVID-19 immunity $(20,21)$ and prevent unintended immune reactions such as vaccine-associated enhanced respiratory disease (VAERD) $(22,23)$. Moreover, spike protein-specific T cell responses directly correlated with binding and neutralizing antibodies, suggesting that the GRAd-COV2 vaccine was able to shape a well-balanced and coordinated cellular and humoral specific immune response, similar to what naturally occurs in mild COVID-19 $(24,25)$.

We detected spike protein-reactive $\mathrm{T}$ cells before vaccination in many otherwise SARS-CoV-2 seronegative volunteers, suggesting that these individuals had memory $\mathrm{T}$ cells from previous seasonal coronaviruses infections. Further supporting this, the frequency of spike protein-reactive $\mathrm{T}$ cells at baseline increased accordingly increasing with volunteers' age. Similar findings have been reported for SARS-CoV-2 unexposed individuals in both immunological studies $(26,27)$. and in COVID-19 vaccines clinical trials (12). Although the spike protein-specific $\mathrm{T}$ cell response was expanded more vigorously in younger compared to older age volunteers vaccinated with GRAd-COV2, the frequency of virus-specific $\mathrm{T}$ cells reached similar frequencies in the two cohorts.

Emerging SARS-CoV-2 variants with amino acid substitutions in the spike protein are becoming predominant, leading to growing concerns over increased transmissibility and decreased vaccine coverage due to immune evasion. Our analysis of a limited set of serum samples from vaccinated individuals suggests that GRAd-COV2-induced neutralizing antibody titers were not reduced against the alpha variant, although were lower against the gamma variant. In fact, several reports have shown partial resistance of SARS-CoV-2 VOCs to vaccine-induced antibodies (28-34). Vaccination with Ad26.COV2.S resulted in five to seven-fold decreases in $\mathrm{IC}_{50}$ titers against the beta variant $(35,36)$ resulting in mean neutralizing antibody titers of 33; this, according to mathematical modeling, could result in decreased protection against infection (7). However, published phase 3 trial data showed that a single dose of Ad26.COV2.S provided $64.0 \%$ protection against moderate to severe disease and $81.7 \%$ 
against severe-critical COVID-19 in a country where $95 \%$ of circulating SARS-CoV-2 was the beta variant (37). Such real world evidence suggests a role for the $\mathrm{T}$ cell response or for non-neutralizing antibody Fc mediated effector functions in maintaining protection against the partially neutralizing antibody-resistant beta variant.

As expected, evidence is emerging that SARS-CoV-2 may evade immune pressure by mutating epitopes recognized by CD8 T cells at the individual level (38). However, these mutations are not often fixed at the population level, possibly due to selective advantage for the variant virus limited to individuals with the relevant allele(s) only. In fact the cellular response induced by natural SARS-CoV-2 infection and vaccination, as reported here for GRAd-COV2, targets many epitopes (27) and is composed of both CD4 and CD8 T cells. CD4 $\mathrm{T}$ cell epitopes are known to be more promiscuous in terms of major histocompatibility complex (MHC) class II restriction and are less impacted by single amino acid mutations. Our observation of a cross-reactive $\mathrm{T}$ cell response to spike at baseline in most of our SARS-CoV-2 spike and N seronegative volunteers also suggest that a subset of the $\mathrm{T}$ cells are memory $\mathrm{T}$ cells developed after prior exposure to seasonal coronaviruses. This also suggests that $\mathrm{T}$ cell responses are induced toward conserved epitopes. Indeed, a study on COVID19 convalescent individuals or recipients of mRNA vaccines (39), as well as a report on Inovio INO-4800 DNA vaccine recipients (40), show that spike protein-specific $\mathrm{T}$ cell responses are only marginally affected by mutations present in the current VOCs. Similarly, we show here that GRAd-COV2induced $\mathrm{T}$ cell responses were largely cross-reactive against all the tested VOCs. Interestingly, a single dose of GRAdCOV2 induced higher median $\mathrm{T}$ cell frequencies specific for both WA1/2020 and VOCs than those measured in COVID-19 convalescent individuals and in recipients of mRNA or DNA vaccines after the second dose (about 1000 SFC for GRAdCOV2 recipients versus about 100 SFC for samples from convalescent individuals and other vaccine recipients).

The description of a rare but serious and potentially lethal complication of vaccine-induced thrombotic thrombocytopenia (VITT) among recipients of ChAdOx1 and Ad26.COV2.S vaccination gave rise to the question whether this is a potential class effect of all adenoviral vector vaccines (41). No corresponding signals have emerged for Sputnik 5 or CanSino vaccines, but so far there is lack of detailed information on safety data. VITT resembles heparin-induced thrombocytopenia (HIT), as it is associated with the induction of plateletactivating autoantibodies against platelet factor 4 (PF4) (42). However, a recent study revealed that PF4 autoantibodies detectable by an ELISA are occasionally elicited by vaccination with both mRNA- and adenoviral vector-based COVID-19 vaccines in the absence of clinical manifestations (43). Therefore, since a positive anti-PF4/polyanion ELISA result alone is not sufficient to diagnose VITT, we have not included such analysis in the present study.

Different mechanisms have been evoked for the adenovirus vector-induced VITT, which are currently under active investigation (44-46) (44-46). However, it would seem unlikely that VITT constitutes a class effect for all adenoviral vector vaccines, since differences among vaccines regarding the adenovirus strain, the spike protein inserts, the manufacturing process and the formulation should theoretically affect the risk of VITT manifestation (47). Indeed, different adenovirus strains may bind to distinct cellular receptors, and hence may infect a different spectrum of host cells (47).

Adenoviral vector vaccines still constitute the bulk of the vaccination program in many countries globally, due to the low costs of a full vaccination course and the considerably simpler storage and transport conditions than those of their mRNA counterparts (48). Furthermore, a single-dose vaccine has provided a viable solution for the rapid achievement of adequate coverage rates of geographically remote areas. Until the complication of VITT is understood, the risk-benefit-ratio of continued use of adenoviral vector vaccines or their restriction to specific age groups or complete withdrawal will depend on the status of viral shedding in the community, and thus should be constantly and dynamically evaluated for their benefits and risks.

As for other candidate vaccines using viral vectors, preexisting immune responses against the vector can compromise the induction of an immune response against the target antigen $(49,50)$ and indeed this was shown also for a candidate COVID-19 vaccine based on the common human Ad5 serotype (15). For simian adenoviruses, pre-existing immunity in humans is mostly due to cross-reactive antibodies originated upon human adenovirus exposure, as suggested by lower frequency of occurrence and definitely lower neutralizing $\mathrm{Ab}$ titers compared to those measured against common human adenoviruses, such as Ad5 (2). In our study, high titers of neutralizing antibodies against GRAd-COV2 were associated with a reduced median $\mathrm{T}$ cell response and reduced concentrations of antibodies specific to the spike protein. However, the presence of pre-existing anti-GRAd antibodies did not abrogate the immune response in most of the volunteers. These findings highlight the potential utility of vectors such as GRAd, for which pre-existing immunity is infrequent in the human population.

So far, pre-existing immunity to GRAd was only assessed in serum samples from US (2) and Italy. However, it is well known and documented for adenovirus of both simian and human origin (51-53) that the prevalence of pre-existing immunity is higher in geographical regions such as sub-Saharan Africa or South-east Asia, possibly related to poorer sanitary conditions. The frequencies of pre-existing immunity to Ad5 and other human adenoviruses can vary depending on the 
serotype and the study population, including its age and place of residency; for example, about $35 \%$ of adults living in US have neutralizing antibodies of any titer to Ad5, whereas prevalence rates increase to over $90 \%$ in individuals living in Cote d'Ivoire $(53,54)$. Antibody prevalence to the rare Ad26 serotype is below $20 \%$ in the US and Europe, but above $90 \%$ in South Africa $(55,56)$. It will be important therefore to extend GRAd seroprevalence studies to world regions outside Europe or the US that are more likely to benefit from adenovirus-based COVID vaccines in the near future.

Our interim analysis indicates that vaccine candidate GRAd-COV2 is safe and immunogenic in both younger and older adults. This finding has supported and guided our decision to proceed with an ongoing phase $2 / 3$ trial (NCT04791423) to evaluate the efficacy of either a single dose or of a two-dose regimen of GRAd-COV2. Indeed, experience from other ongoing clinical trials on adenovirus-based vaccines provided evidence that a second administration of vaccine is safe and can improve the production of SARS-CoV-2 neutralizing antibodies $(12,13)$. The observed increase of antiGRAd neutralizing antibody titers post vaccination is in line with that observed with other adenovirus based COVID-19 vaccines $(9,10)$, which did not prevent boosting of anti-spike protein antibodies upon a second administration. It is worth noting that most of the COVID-19 vaccines require a primeboost scheme, including non-replicating viral vectored vaccines, mRNA and adjuvanted subunit vaccines.

This study has some limitations due to the low number of volunteers per arm $(n=15)$, and to the lack of participant randomization amongst study arms on the basis of GRAd neutralizing titer at baseline. Both these aspects could have had an impact in the poor vaccine dose response effect observed. However, the explored dose range (four-fold between low and high dose) was limited, and no major dose effect was expected. Nevertheless, a high dose vaccine $\left(2 \times 10^{11}\right.$ viral particles) was selected for an ongoing phase $2 / 3$ single-dose trial, due to higher and more consistent immunogenicity especially in the elderly cohort. As for studies evaluating a two-dose regimen, the intermediate dose of $1 \times 10^{11}$ viral particles was selected, as it represents the best compromise between tolerability and immunogenicity. Another limitation lies in the choice of immunological assays that, at the present stage, do not allow for easy comparison with immunogenicity of other vaccines. Finally, data beyond w4 post vaccination on persistence of humoral and cellular responses will be part of a future report once the study follow up is completed.

In summary we present here favorable interim safety and immunogenicity results of GRAd-COV2 phase 1 trial. GRAdCOV2 was well tolerated and induced humoral and cellular responses to SARS-CoV-2 spike antigen similarly in younger and older adults. Thus, GRAd-COV2 merits further consideration as a SARS-CoV-2 vaccine candidate.

\section{MATERIALS AND METHODS \\ Study design}

This study is a phase 1, dose-escalation, open label clinical trial designed to determine the safety and immunogenicity of GRAd-COV2. The study included two age cohorts, of either younger (18 to 55) or older (65 to 85) adults. No formal sample size calculation was carried out. Each cohort consisted of 3 arms of 15 volunteers each, for assessing a single administration at three different doses of GRAd-COV2: low dose $\left(5 \times 10^{10}\right.$ viral particles), intermediate dose ( $1 \times 10^{11}$ viral particles), and high dose $\left(2 \times 10^{11}\right.$ viral particles). We report here the safety and immunogenicity endpoints collected in the first 4 weeks after vaccination for the volunteers enrolled in both age cohorts, as foreseen in the study Protocol (Interim analyses 1 and 2). The full study protocol is provided in supplementary material. Eligible participants were healthy adults aged 18 to 55 years with no history of COVID-19, no laboratory findings suggestive of current or previous infection with SARS-COV-2 and who have attended the screening visit no more than 21 days before vaccination.

GRAd-COV2 $(\triangle \mathrm{E} 1, \triangle \mathrm{E} 3, \triangle \mathrm{E} 4)$ was manufactured by ReiThera under good manufacturing practice conditions in the proprietary cell line ReiCell35S (a suspension adapted packaging cell line derivative of HEK293) and purified by an extensive downstream process including host cell DNA precipitation, depth filtration, two chromatographic purification steps followed by nuclease digestion and ultrafiltration. The clinical material was finally formulated in formulation buffer at a concentration of $2 \times 10^{11}$ viral particles $/ \mathrm{ml}$. Volunteers received a single intramuscular injection in the deltoid. For administration of the high dose, $1 \mathrm{ml}$ of GRAd-COV2 was injected without dilution. For low dose and intermediate dose arms, the vaccine was diluted in sterile saline solution to reach a final $1 \mathrm{ml}$ injection volume. Volunteers were expected to attend several visits, at day 2 , week 1 , week 2 and week 4, week 8 , week 12 and week 24 after vaccination. During the visit, the volunteers underwent blood sampling and medical evaluation. Participants also discussed with a doctor any potential AEs.

The dose-escalation staggered enrollment included 3 sentinel volunteers in the low dose arm followed by enrollment of the full low dose arm. Intermediate and high dose sentinel volunteers were enrolled 7 days after that safety data of low dose or intermediate dose arms were available, respectively. All the enrollment, stages were supervised by an independent data safety monitoring board. Volunteers recorded local and systemic reactions on a diary card for 28 days. The severity and relatedness with vaccination or adverse events were assessed by the medical team in each center.

\section{Safety assessment}

Solicited adverse events are foreseeable AEs following vaccination with GRAd-COV2, and include injection site pain, 
erythema, swelling, myalgia, headache, fatigue, fever, chills, nausea, vomiting, diarrhea, ulceration, and abdominal pain. All these events were recorded on the diary card by volunteers and investigated by doctor at each visit. Unsolicited adverse events are all those events that were directly reported by the volunteers or emerged in any other way during visits. Severity of AEs has been assessed according to the Common Terminology Criteria for Adverse Events Version 5 into mild, moderate, and severe. A serious adverse event is an event that results either in death, life-threatening condition, persistent disability/incapacity, hospitalization or congenital anomaly/birth defect (specific definitions are reported in the main protocol file in section 10).

As comparator for immunogenicity analysis, we used three independent sets of anonymized specimens (serum and PBMCs) from COVID-19 patients either hospitalized or recovering from mild symptomatic disease, collected 20 to 60 days after symptom onset. A reference anti-SARS-CoV-2 plasma sample from National Institute for Biological Standards and Control (NIBSC, code 20/130), acquired from a donor who recovered from COVID-19, was included as a positive control.

\section{Ethical statement}

All participants provided written informed consent before enrolment. The trial was conducted at the National Institute for Infectious Diseases Lazzaro Spallanzani (INMI) in Rome and at Centro Ricerche Cliniche in Verona (CRC-Verona). The study was conducted according to the Declaration of Helsinki, and approved by the Italian Regulatory Drug Agency (AIFA) and the Italian National Ethical Committee for COVID-19 clinical studies (ClinicalTrials.gov NCT04528641; EudraCT 2020-002835-31). Serum samples from convalescent patients who resolved SARS-CoV-2 infections came from residual specimens used for diagnostic purposes and were utilized according to INMI protocols for observational studies approved form internal ethical committee.

SARS-COV-2 anti-spike protein and anti-nucleoprotein IgG high throughput Chemiluminescence Immunoassay

Two commercial assays were used according to manufacturer's protocols. DiaSorin LIAISON SARS-CoV-2 S1/S2 IgG test is a CLIA detecting anti-S1/S2 IgG on LIAISON XL analyzers. IgG antibody concentrations are expressed as arbitrary units (AU) per $\mathrm{ml}$, with $\mathrm{AU} / \mathrm{ml} \geq 15$ considered positive. The Abbott SARS-CoV-2 assay is a chemiluminescence microparticle assay (CMIA) detecting anti-N protein IgG and is run on an Abbott ARCHITECT i2000sr. An index value sample cut-off $\geq 1.4$ was considered positive. Assays were performed according to manufacturer's instructions.

\section{SARS-CoV-2 Spike and RBD ELISA}

SARS-CoV-2 ELISA was developed using either SARSCoV-2 full length soluble prefusion stabilized Spike protein (expressed in Expi293 cells at ReiThera) or a recombinant
RBD (expressed in HEK293 cells, ACROBiosystems) as coated antigens. Proteins were coated on NUNC Maxisorp plates (Thermo Fisher Scientific) at optimized concentration (5 $\mu \mathrm{g} / \mathrm{ml}$ for R121, $2.5 \mu \mathrm{g} / \mathrm{ml}$ for RBD) in phosphate-buffered saline (PBS) overnight at $4^{\circ} \mathrm{C}$. The following day, plates were washed with PBS 0,05\% Tween-20 (PBS-T), then blocked with PBS-T+3\% non-fat dry milk for 1.5 hours at $25^{\circ} \mathrm{C}$ with shaking. After wash, serum dilution curves (six 3-fold serial dilution from 1:100 to 1:24300) prepared in PBS-T+1\% non-fat dried milk were plated and incubated for 2 hours at $25^{\circ} \mathrm{C}$ with shaking. Plates were then washed and incubated with 1:2000 diluted anti-human IgG (Fc-specific, Sigma-Aldrich) for 1 hour at $25^{\circ} \mathrm{C}$ with shaking. Plates were then washed one last time and incubated with alkaline phosphatase substrate SigmaFast (Sigma-Aldrich) at $25^{\circ} \mathrm{C}$. Absorbance was read at 405 and $620 \mathrm{~nm}$ using EnSight multiple plate reader (Perkin Elmer), at 10, 20 and $30 \mathrm{~min}$; the read with the best Rsquared value was used to calculate endpoint titers. The endpoint titer was defined as the highest serum dilution that resulted in an absorbance value (OD, optical density) just above the calculated background of 4-fold the OD from secondary antibody alone. A COVID-19 convalescent patient's serum at 1:200 and 1:6400 dilution was included as positive control in each plate to ensure inter-assay reproducibility. Anti-SARSCoV-2 plasma (NIBSC code 20/130) was used as standard reference in each experiment.

\section{SARS-CoV-2 microneutralization assay (MNA)}

Serum samples collected from vaccinated volunteers or convalescent COVID-19 patients were heat-inactivated at $56^{\circ} \mathrm{C}$ for $30 \mathrm{~min}$, and titrated in duplicate in 7 two-fold serial dilutions (starting dilution 1:10). Equal volumes of $100 \mathrm{TCID}_{50}$ (Tissue Culture Infectious Dose 50\%) of SARS-CoV-2 (strain 2019-nCoV/Italy-INMI1; GISAID accession ID: EPI_ISL_412974) and serum dilutions were mixed and incubated at $37^{\circ} \mathrm{C} 5 \% \mathrm{CO}_{2}$ for $30 \mathrm{~min}$. Subsequently, 96 -well tissue culture plates with sub-confluent VeroE6 cell (ATCC) monolayers were infected with $100 \mu \mathrm{l} /$ well of virus-serum mixtures and incubated at $37^{\circ} \mathrm{C}$ and $5 \% \mathrm{CO}_{2}$. To standardize inter-assay procedures, positive control samples showing high (1:160) and low (1:40) neutralizing activity were included in each MNA assay. After 48 hours, microplates were observed by light microscope for the presence of CPE. The supernatant of each plate was carefully discarded and $120 \mu \mathrm{l}$ of a Crystal Violet solution containing $2 \%$ formaldehyde was added to each well. After $30 \mathrm{~min}$, the fixing solution was removed by washing with tap water and cell viability measured by photometer at $595 \mathrm{~nm}$ (Synergy HTX Multi-Mode Microplate Reader, Biotek). The highest serum dilution inhibiting at least $90 \%$ of the CPE was indicated as the neutralization titer and expressed as the reciprocal of serum dilution $\left(\mathrm{MNA}_{90}\right)$. Serum from the NIBSC with known neutralization titer was used as reference in MNA (NIBSC code 20/130). Where indicated, two 
alternative viral strains were used to test serum samples neutralizing activity against SARS-CoV-2 variants of concern (hCoV-19/Italy/LAZ-INMI-129/2020 lineage B.1.1.7, GISAID accession ID: EPI_ISL_765567 and hCoV-19/Italy/LAZ-INMI216isl/2021 lineage P.1, GISAID accession ID: EPI_ISL_1023524).

\section{SARS-CoV-2 plaque reduction neutralization test (PRNT)}

As an exploratory endpoint, the SARS-CoV-2 PRNT Po $_{50}$ titers of vaccinated volunteers' serum samples were determined by means of a plaque reduction neutralization test (PRNT) developed and run at Viroclinics Biosciences. Briefly, a standard number of SARS-CoV-2 (Bav/Pat1/2020 strain) infectious units were incubated with eight two-fold serial dilutions of heat inactivated serum, starting from 1:8 and up to 1:1024. After a 1 hour pre-incubation, the virus/serum mixtures were inoculated on VeroE6 cells (ATCC) for 1 hour, than washed, replaced with infection medium and the cells were left overnight. After 16 to 24 hours, the cells were formalin-fixed, permeabilized with ethanol, and incubated with primary antiSARS-CoV-2 nucleocapsid monoclonal antibody (Sino Biological) followed by a secondary anti-mouse IgG horseradish peroxidase conjugate (Life Technologies) and TrueBlue substrate, which forms a blue precipitate on positive cells. Images of all wells were acquired by an ImmunoSpot analyzer (Cellular Technology Limited, CTL), equipped with software capable to accurately count the virus positive cells. The $50 \%$ neutralization titers were calculated according to a method described earlier (57). The NIBSC standard 20/130 was used as a reference in the same assay as the RT-COV-2 trial serum samples, with resulting $\mathrm{PRNT}_{50}$ of 697 and 934 for younger and older adults assay runs, respectively.

\section{GRAd Neutralizing Antibody Assay}

Neutralizing antibody (nAb) titers in human serum samples were assayed as previously described (58). Briefly, $8 \times 10^{4}$ HEK293 cells per well were seeded in 96 well plates the day before the assay. GRAd vector encoding the reporter gene secreted alkaline phosphatase (SEAP) at a pre-optimized multiplicity of infection (MOI) was preincubated for 1 hour at $37^{\circ} \mathrm{C}$ alone or with serial dilutions of control or test serum samples. Samples were then added to the $80-90 \%$ confluent HEK293 cells. After incubation for 1 hour at $37^{\circ} \mathrm{C}$, the serum/infection mix was removed and replaced with $10 \%$ fetal bovine serum (FBS, Cytiva HyClone) in Dulbecco's Modified Eagle Medium (DMEM, Thermo Fisher). SEAP expression was measured 24 hours later in cell supernatant by means of the chemiluminescent substrate from the Phospha-Light kit (Applied Biosystems). Neutralization titers were defined as the dilution at which a 50\% reduction of SEAP activity from serum sample was observed relative to SEAP activity from virus alone.

\section{PBMC isolation and stimulation}

Peripheral venous blood $(40 \mathrm{ml})$ was collected in $7 \mathrm{ml}$ lithium-heparin Vacutest blood collection tubes (Kima). PBMCs were isolated from peripheral blood by density gradient centrifugation (Histopaque 1077, Sigma-Aldrich). After separation, PBMCs were suspended in RPMI-1640 (Sigma-Aldrich) supplemented with $10 \%$ heat-inactivated highly defined FBS (Cytiva HyClone), $2 \mathrm{mmol} / \mathrm{L}$ L-glutamine, $10 \mathrm{mmol} / \mathrm{L}$ HEPES buffer (N-2-hydroxyethylpiperazine-N-2-ethane sulfonic acid, Sigma-Aldrich), $100 \mathrm{U} / \mathrm{ml}$ penicillin, and $100 \mu \mathrm{g} / \mathrm{ml}$ streptomycin (Gibco), hereafter termed R10. PBMC count and viability were performed by using Guava Muse (Luminex). $12 \times 10^{6}$ PBMC were immediately used in ELISpot and intracellular staining experiments (at week 2 visit only). The remaining PBMCs were immediately frozen in FBS plus 10\% dimethyl sulfoxide (DMSO).

PBMCs were thawed quickly in $37^{\circ} \mathrm{C}$ water bath with thawing medium [CTL Wash supplemented medium in RPMI-1640 (Sigma-Aldrich) and supplementing with L-glutamine (Gibco) and Benzonase (Merck) 50U/ml]. After one wash, PBMC were resuspended into $50 \mathrm{ml}$ polypropylene vented cap tubes with prewarm R10 medium, counted and rested at $2 \times 10^{6}$ cells $/ \mathrm{ml}$ at $37^{\circ} \mathrm{C}$ and $5 \%$ of $\mathrm{CO}_{2}$ for at least 16 hours. PBMCs were then counted, resuspended at $4 \times 10^{6}$ cell/ml in R10 medium and used in ELISpot assays.

A set of 316 15mer peptides overlapping by 11 amino acids (synthetized by Elabscience Biotech Inc, and distributed by TEMA RICERCA), designed to cover the full-length spike protein, was arranged into 4 pools (S1a, S1b-including RBD domain, S2a and S2b).

Freshly isolated PBMCs $\left(2 \times 10^{6} / \mathrm{ml}\right)$ were stimulated with the four spike peptides pools (S1a, S1b, S2a, S2b) for 18 hours $(3 \mu \mathrm{g} / \mathrm{ml}$ each peptide final concentration). Thawed PBMCs $\left(2 \times 10^{6} / \mathrm{ml}\right)$ were stimulated with two spike peptides pools $(\mathrm{S} 1 \mathrm{a}+\mathrm{S} 1 \mathrm{~b}$ and $\mathrm{S} 2 \mathrm{a}+\mathrm{S} 2 \mathrm{~b})$ for 18 hours $(3 \mu \mathrm{g} / \mathrm{ml}$ each peptide final concentration). For flow cytometry experiments, brefeldin A (10ug/ml, Sigma-Aldrich) was added. Different 15mer S1 and S2 peptide pools spanning the spike protein of the Wuhan reference strain, and of the lineages B.1.1.7 (alpha), B.1.351 (beta), P.1 (gamma), and B.1.429 (epsilon) $(1 \mu \mathrm{g} / \mathrm{ml}$ each peptide final concentration, JPT, Germany) were also used in a sample of 12 volunteers to analyze the reactivity of $\mathrm{T}$ cells against $\mathrm{SARS}-\mathrm{CoV}-2$ variants.

\section{IFN- $\gamma$ ELISpot assay}

The frequency of IFN- $\gamma$-producing T cells was assessed by enzyme-linked immunosorbent spot-forming cell assay (ELISpot) after specific stimulation. Freshly isolated or thawed PBMCs were resuspended in R10, stimulated with peptides pools, as described above, and plated at $2 \times 10^{5}$ cells/well in ELISpot plates (Human IFN-ץ ELISpot plus kit; Mabtech). PBMCs were incubated for 18 to 20 hours with $5 \%$ $\mathrm{CO}_{2}$. At the end of incubation, the ELISpot assay was developed according to manufacturer's instructions. Spontaneous 
cytokine production (background) was assessed by incubating PBMCs with DMSO (Sigma-Aldrich), which was used to dilute peptides. Results are expressed as spot forming cells (SFC) per $10^{6}$ PBMCs in stimulating cultures after subtracting spontaneous background. A result was considered positive if matching two criteria: i) higher than $>48 \mathrm{SFC} / 10^{6} \mathrm{PBMCs}$ and ii) higher than 3 times the background value. Data from three volunteers (in experiments with freshly isolated PBMCs) and from nine volunteers (in experiments with thawed PBMCs) were excluded from all ELISpot analyses since their spontaneous IFN- $\gamma$ secretion in DMSO wells was above the mean +3 standard deviation of the study population (mean $=42 \mathrm{SFC}$, $\mathrm{SD}=72.27$, mean $+3 \mathrm{SD}=258 \mathrm{SFC} /$ million $\mathrm{PBMCs}$ ), leading to unreliable quantitative analysis.

\section{Intracellular staining and flow-cytometry}

Intracellular flow cytometry was performed by using ViaKrome 808 Fixable viability dye, anti-IL-17A Alexa Fluor 700, anti-CD45 Krome Orange, (all three from Beckman Coulter), anti-CD3 BUV661, anti-CD8 Peridinin-Chlorophyll-Protein (PerCP), anti-CD4 V450, anti-IL-2 fluorescein isothiocyanate (FITC), anti-IL4 phycoerythrin (PE), (all five from BD Biosciences), and anti-IFN- $\curlyvee$ PE-Vio770 (from Miltenyi Biotec). Briefly, PBMCs were washed in Dulbecco's PBS (DPBS, Corning) and stained with 1:20 diluted ViaKrome 808 Fixable Viability dye, anti-CD45, anti-CD3, anti-CD8, anti$\mathrm{CD} 4$ for $15 \mathrm{~min}$ at $4{ }^{\circ} \mathrm{C}$. After washing cells were fixed with $1 \%$ paraformaldehyde (PFA, Electron Microscopy Science), then stained with 1:20 diluted anti-IL-17A, anti-IL-2, anti-IL-4 and anti-IFN- $\gamma$ in PBS (Corning) plus $0.5 \%$ bovine serum albumin (BSA, Sigma-Aldrich), 0.01\% sodium azide (Serva Serving Scientists), and $0.5 \%$ saponin (Sigma-Aldrich) for $30 \mathrm{~min}$ at room temperature. Acquisition of 200,000 events was performed in the $\mathrm{CD}^{+}$gated population on a CytoFLEX LX flow cytometer, and analyzed with CytExpert software (Beckman Coulter). Data were analyzed with CytExpert software (Beckman Coulter: doublets were excluded in the forward scatter height (FSC-H)/forward scatter area (FSC-A) dot plot. Live cells were selected as Viakrome negative cells. Next, CD45 ${ }^{+}$ were gated, followed by gating of $\mathrm{CD}^{+}$lymphocytes. Among the $\mathrm{CD}^{+}$cells, $\mathrm{CD}^{+}$or $\mathrm{CD}^{+}$cells were selected and the percentage $\mathrm{CD} 4$ or $\mathrm{CD} 8 \mathrm{~T}$ cells producing cytokines were evaluated. Spontaneous cytokine production (DMSO stimulation) was subtracted. The gating strategy is shown in Supplementary Materials (fig. S5)

\section{Statistical analysis}

Categorical variables, including occurrence of adverse events (AE) and detection of binding and neutralizing antibodies against SARS-CoV-2 and GRAd were reported as proportions. Continuous variables, including results of CLIA anti-spike protein IgG, $\mathrm{MNA}_{90}$ titers, $\mathrm{PNRT}_{50}$ titers and ELISpot values for IFN- $\gamma$ secretion, were reported as median and interquartile range. Comparison of medians across arms and the impact of pre-existing immunity against GRAd were evaluated by a two-tailed Kruskal-Wallis one-way variance analysis. Associations between categorical variables were carried out using Fisher's exact test. Correlations between immunogenicity assays were assessed by non-parametric Spearman's rank tests. Data in Fig. 6 were analyzed by Friedman's test with Dunn's multiple comparisons correction. Raw, individual-level data are presented in data file S1.

\section{SUPPLEMENTARY MATERIALS}

www.science.org/doi/10.1126/scitranslmed.abj1966

Figs. S1 to S5

Tables S1 and S2

RT-CoV-2 study protocol

Data File S1

\section{REFERENCES AND NOTES}

1. https://www.who.int/publications/m/item/draft-landscape-of-covid-19candidate-vaccines.

2. S. Capone, A. Raggioli, M. Gentile, S. Battella, A. Lahm, A. Sommella, A. M. Contino, R. A. Urbanowicz, R. Scala, F. Barra, A. Leuzzi, E. Lilli, G. Miselli, A. Noto, M. Ferraiuolo, F. Talotta, T. Tsoleridis, C. Castilletti, G. Matusali, F. Colavita, D. Lapa, S. Meschi, M. Capobianchi, M. Soriani, A. Folgori, J. K. Ball, S. Colloca, A. Vitelli, Immunogenicity of a new gorilla adenovirus vaccine candidate for COVID-19. Mol. Ther. 29, 2412-2423 (2021). doi:10.1016/j.ymthe.2021.04.022 Medline

3. L. Dai, G. F. Gao, Viral targets for vaccines against COVID-19. Nat. Rev. Immunol. 21, 73-82 (2021). doi:10.1038/s41577-020-00480-0 Medline

4. J. Pallesen, N. Wang, K. S. Corbett, D. Wrapp, R. N. Kirchdoerfer, H. L. Turner, C. A. Cottrell, M. M. Becker, L. Wang, W. Shi, W. P. Kong, E. L. Andres, A. N. Kettenbach, M. R. Denison, J. D. Chappell, B. S. Graham, A. B. Ward, J. S. McLellan, Immunogenicity and structures of a rationally designed prefusion MERS-CoV spike antigen. Proc. Natl. Acad. Sci. U.S.A. 114, E7348-E7357 (2017). doj:10.1073/pnas.1707304114 Medline

5. D. Wrapp, N. Wang, K. S. Corbett, J. A. Goldsmith, C. L. Hsieh, O. Abiona, B. S. Graham, J. S. McLellan, Cryo-EM structure of the 2019-nCoV spike in the prefusion conformation. Science 367, 1260-1263 (2020). doi:10.1126/science.abb2507 Medline

6. K. A. Earle, D. M. Ambrosino, A. Fiore-Gartland, D. Goldblatt, P. B. Gilbert, G. R. Siber, P. Dull, S. A. Plotkin, Evidence for antibody as a protective correlate for COVID-19 vaccines. Vaccine 39, 4423-4428 (2021). doi:10.1016/j.vaccine.2021.05.063 Medline

7. D. S. Khoury, D. Cromer, A. Reynaldi, T. E. Schlub, A. K. Wheatley, J. A. Juno, K. Subbarao, S. J. Kent, J. A. Triccas, M. P. Davenport, Neutralizing antibody levels are highly predictive of immune protection from symptomatic SARS-CoV-2 infection. Nat. Med. 27, 1205-1211 (2021). doi:10.1038/s41591-021-01377-8 Medline

8. F. P. Polack, S. J. Thomas, N. Kitchin, J. Absalon, A. Gurtman, S. Lockhart, J. L. Perez, G. Pérez Marc, E. D. Moreira, C. Zerbini, R. Bailey, K. A. Swanson, S. Roychoudhury, K. Koury, P. Li, W. V. Kalina, D. Cooper, R. W. Frenck Jr., L. L. Hammitt, Ö. Türeci, H. Nell, A. Schaefer, S. Ünal, D. B. Tresnan, S. Mather, P. R. Dormitzer, U. Şahin, K. U. Jansen, W. C. Gruber; C4591001 Clinical Trial Group, Safety and Efficacy of the BNT162b2 mRNA Covid-19 Vaccine. N. Engl. J. Med. 383, 2603-2615 (2020). doi:10.1056/NEJMoa2034577 Medline

9. M. N. Ramasamy, A. M. Minassian, K. J. Ewer, A. L. Flaxman, P. M. Folegatti, D. R. Owens, M. Voysey, P. K. Aley, B. Angus, G. Babbage, S. Belij-Rammerstorfer, L. Berry, S. Bibi, M. Bittaye, K. Cathie, H. Chappell, S. Charlton, P. Cicconi, E. A. Clutterbuck, R. Colin-Jones, C. Dold, K. R. W. Emary, S. Fedosyuk, M. Fuskova, D. Gbesemete, C. Green, B. Hallis, M. M. Hou, D. Jenkin, C. C. D. Joe, E. J. Kelly, S. Kerridge, A. M. Lawrie, A. Lelliott, M. N. Lwin, R. Makinson, N. G. Marchevsky, Y. Mujadidi, A. P. S. Munro, M. Pacurar, E. Plested, J. Rand, T. Rawlinson, S. Rhead, H. Robinson, A. J. Ritchie, A. L. Ross-Russell, S. Saich, N. Singh, C. C. Smith, M. D. Snape, R. Song, R. Tarrant, Y. Themistocleous, K. M. Thomas, T. L. Villafana, S. C. Warren, M. E. E. Watson, A. D. Douglas, A. V. S. Hill, T. Lambe, S. C. Gilbert, S. N. Faust, A. J. Pollard; Oxford COVID Vaccine Trial Group, Safety and 
immunogenicity of ChAdOX1 nCoV-19 vaccine administered in a prime-boost regimen in young and old adults (COVO02): A single-blind, randomised, controlled, phase 2/3 trial. Lancet 396, 1979-1993 (2021). doi:10.1016/S01406736(20)32466-1 Medline

10. J. Sadoff, M. Le Gars, G. Shukarev, D. Heerwegh, C. Truyers, A. M. de Groot, J. Stoop, S. Tete, W. Van Damme, I. Leroux-Roels, P. J. Berghmans, M. Kimmel, P. Van Damme, J. de Hoon, W. Smith, K. E. Stephenson, S. C. De Rosa, K. W. Cohen, M. J. McElrath, E. Cormier, G. Scheper, D. H. Barouch, J. Hendriks, F. Struyf, M. Douoguih, J. Van Hoof, H. Schuitemaker, Interim Results of a Phase 1-2a Trial of Ad26.COV2.S Covid-19 Vaccine. N. Engl. J. Med. 384, 1824-1835 (2021). doi:10.1056/NEJMoa2034201 Medline

11. P. M. Folegatti, M. Bittaye, A. Flaxman, F. R. Lopez, D. Bellamy, A. Kupke, C. Mair, R. Makinson, J. Sheridan, C. Rohde, S. Halwe, Y. Jeong, Y. S. Park, J. O. Kim, M. Song, A. Boyd, N. Tran, D. Silman, I. Poulton, M. Datoo, J. Marshall, Y. Themistocleous, A. Lawrie, R. Roberts, E. Berrie, S. Becker, T. Lambe, A. Hill, K. Ewer, S. Gilbert, Safety and immunogenicity of a candidate Middle East respiratory syndrome coronavirus viral-vectored vaccine: A dose-escalation, open-label, non-randomised, uncontrolled, phase 1 trial. Lancet Infect. Dis. 20, 816-826 (2020). doi:10.1016/S1473-3099(20)30160-2 Medline

12. P. M. Folegatti, K. J. Ewer, P. K. Aley, B. Angus, S. Becker, S. Belij-Rammerstorfer, D. Bellamy, S. Bibi, M. Bittaye, E. A. Clutterbuck, C. Dold, S. N. Faust, A. Finn, A. L. Flaxman, B. Hallis, P. Heath, D. Jenkin, R. Lazarus, R. Makinson, A. M. Minassian, K. M. Pollock, M. Ramasamy, H. Robinson, M. Snape, R. Tarrant, M. Voysey, C. Green, A. D. Douglas, A. V. S. Hill, T. Lambe, S. C. Gilbert, A. J. Pollard; Oxford COVID Vaccine Trial Group, Safety and immunogenicity of the ChAdOx1 nCoV-19 vaccine against SARS-CoV-2: A preliminary report of a phase 1/2, single-blind, randomised controlled trial. Lancet 396, 467-478 (2020). doi:10.1016/S01406736(20)31604-4 Medline

13. D. Y. Logunov, I. V. Dolzhikova, O. V. Zubkova, A. I. Tukhvatulin, D. V. Shcheblyakov, A. S. Dzharullaeva, D. M. Grousova, A. S. Erokhova, A. V. Kovyrshina, A. G. Botikov, F. M. Izhaeva, O. Popova, T. A. Ozharovskaya, I. B. Esmagambetov, I. A. Favorskaya, D. I. Zrelkin, D. V. Voronina, D. N. Shcherbinin, A. S. Semikhin, Y. V. Simakova, E. A. Tokarskaya, N. L. Lubenets, D. A. Egorova, M. M. Shmarov, N. A. Nikitenko, L. F. Morozova, E. A. Smolyarchuk, E. V. Kryukov, V. F. Babira, S. V. Borisevich, B. S. Naroditsky, A. L. Gintsburg, Safety and immunogenicity of an rAd26 and rAd5 vector-based heterologous prime-boost COVID-19 vaccine in two formulations: Two open, non-randomised phase 1/2 studies from Russia. Lancet 396, 887-897 (2020). doi:10.1016/S0140-6736(20)31866-3 Medline

14. F. C. Zhu, X. H. Guan, Y. H. Li, J. Y. Huang, T. Jiang, L. H. Hou, J. X. Li, B. F. Yang, L. Wang, W. J. Wang, S. P. Wu, Z. Wang, X. H. Wu, J. J. Xu, Z. Zhang, S. Y. Jia, B. S. Wang, Y. Hu, J. J. Liu, J. Zhang, X. A. Qian, Q. Li, H. X. Pan, H. D. Jiang, P. Deng, J. B. Gou, X. W. Wang, X. H. Wang, W. Chen, Immunogenicity and safety of a recombinant adenovirus type-5-vectored COVID-19 vaccine in healthy adults aged 18 years or older: A randomised, double-blind, placebo-controlled, phase 2 trial. Lancet 396, 479-488 (2020). doi:10.1016/S0140-6736(20)31605-6 Medline

15. F. C. Zhu, Y. H. Li, X. H. Guan, L. H. Hou, W. J. Wang, J. X. Li, S. P. Wu, B. S. Wang, Z. Wang, L. Wang, S. Y. Jia, H. D. Jiang, L. Wang, T. Jiang, Y. Hu, J. B. Gou, S. B. Xu, J. J. Xu, X. W. Wang, W. Wang, W. Chen, Safety, tolerability, and immunogenicity of a recombinant adenovirus type-5 vectored COVID-19 vaccine: A doseescalation, open-label, non-randomised, first-in-human trial. Lancet 395, 18451854 (2020). doi:10.1016/S0140-6736(20)31208-3 Medline

16. L. A. Jackson, E. J. Anderson, N. G. Rouphael, P. C. Roberts, M. Makhene, R. N. Coler, M. P. McCullough, J. D. Chappell, M. R. Denison, L. J. Stevens, A. J. Pruijssers, A. McDermott, B. Flach, N. A. Doria-Rose, K. S. Corbett, K. M. Morabito, S. O'Dell, S. D. Schmidt, P. A. Swanson 2nd, M. Padilla, J. R. Mascola, K. M. Neuzil, H. Bennett, W. Sun, E. Peters, M. Makowski, J. Albert, K. Cross, W. Buchanan, R. Pikaart-Tautges, J. E. Ledgerwood, B. S. Graham, J. H. Beigel; mRNA-1273 Study Group, An mRNA Vaccine against SARS-CoV-2 - Preliminary Report. N. Engl. J. Med. 383, 1920-1931 (2020). doi:10.1056/NEJMoa2022483 Medline

17. C. Keech, G. Albert, I. Cho, A. Robertson, P. Reed, S. Neal, J. S. Plested, M. Zhu, S. Cloney-Clark, H. Zhou, G. Smith, N. Patel, M. B. Frieman, R. E. Haupt, J. Logue, M. McGrath, S. Weston, P. A. Piedra, C. Desai, K. Callahan, M. Lewis, P. Price-Abbott, N. Formica, V. Shinde, L. Fries, J. D. Lickliter, P. Griffin, B. Wilkinson, G. M. Glenn, Phase 1-2 Trial of a SARS-CoV-2 Recombinant Spike Protein Nanoparticle
Vaccine. N. Engl. J. Med. 383, 2320-2332 (2020). doi:10.1056/NEJMoa2026920 Medline

18. E. J. Anderson, N. G. Rouphael, A. T. Widge, L. A. Jackson, P. C. Roberts, M. Makhene, J. D. Chappell, M. R. Denison, L. J. Stevens, A. J. Pruijssers, A. B. McDermott, B. Flach, B. C. Lin, N. A. Doria-Rose, S. O'Dell, S. D. Schmidt, K. S. Corbett, P. A. Swanson 2nd, M. Padilla, K. M. Neuzil, H. Bennett, B. Leav, M. Makowski, J. Albert, K. Cross, V. V. Edara, K. Floyd, M. S. Suthar, D. R. Martinez, R. Baric, W. Buchanan, C. J. Luke, V. K. Phadke, C. A. Rostad, J. E. Ledgerwood, B. S. Graham, J. H. Beigel; mRNA-1273 Study Group, Safety and Immunogenicity of SARS-CoV-2 mRNA-1273 Vaccine in Older Adults. N. Engl. J. Med. 383, 24272438 (2020). doi:10.1056/NEJMoa2028436 Medline

19. E. E. Walsh, R. W. Frenck Jr., A. R. Falsey, N. Kitchin, J. Absalon, A. Gurtman, S. Lockhart, K. Neuzil, M. J. Mulligan, R. Bailey, K. A. Swanson, P. Li, K. Koury, W. Kalina, D. Cooper, C. Fontes-Garfias, P. Y. Shi, Ö. Türeci, K. R. Tompkins, K. E. Lyke, V. Raabe, P. R. Dormitzer, K. U. Jansen, U. Şahin, W. C. Gruber, Safety and Immunogenicity of Two RNA-Based Covid-19 Vaccine Candidates. N. Engl. J. Med. 383, 2439-2450 (2020). doi:10.1056/NEJMoa2027906 Medline

20. H. F. Sewell, R. M. Agius, D. Kendrick, M. Stewart, Covid-19 vaccines: Delivering protective immunity. BMJ 371, m4838 (2020). doi:10.1136/bmi.m4838 Medline

21. J. Zuo, A. C. Dowell, H. Pearce, K. Verma, H. M. Long, J. Begum, F. Aiano, Z. AminChowdhury, K. Hoschler, T. Brooks, S. Taylor, J. Hewson, B. Hallis, L. Stapley, R. Borrow, E. Linley, S. Ahmad, B. Parker, A. Horsley, G. Amirthalingam, K. Brown, M. E. Ramsay, S. Ladhani, P. Moss, Robust SARS-CoV-2-specific T cell immunity is maintained at 6 months following primary infection. Nat. Immunol. 22, 620-626 (2021). doi:10.1038/s41590-021-00902-8 Medline

22. B. S. Graham, Rapid COVID-19 vaccine development. Science 368, 945-946 (2020). doi:10.1126/science.abb8923 Medline

23. B. F. Haynes, L. Corey, P. Fernandes, P. B. Gilbert, P. J. Hotez, S. Rao, M. R. Santos, H. Schuitemaker, M. Watson, A. Arvin, Prospects for a safe COVID-19 vaccine. Sci. Transl. Med. 12, eabe0948 (2020). doi:10.1126/scitranslmed.abe0948 Medline

24. Z. Chen, E. John Wherry, T cell responses in patients with COVID-19. Nat. Rev. Immunol. 20, 529-536 (2020). doi:10.1038/s41577-020-0402-6 Medline

25. N. Vabret, G. J. Britton, C. Gruber, S. Hegde, J. Kim, M. Kuksin, R. Levantovsky, L. Malle, A. Moreira, M. D. Park, L. Pia, E. Risson, M. Saffern, B. Salomé, M. Esai Selvan, M. P. Spindler, J. Tan, V. van der Heide, J. K. Gregory, K. Alexandropoulos, N. Bhardwaj, B. D. Brown, B. Greenbaum, Z. H. Gümüş, D. Homann, A. Horowitz, A. O. Kamphorst, M. A. Curotto de Lafaille, S. Mehandru, M. Merad, R. M. Samstein, P. Sinai; Sinai Immunology Review Project, Immunology of COVID-19: Current State of the Science. Immunity 52, 910-941 (2020). doi:10.1016/i.immuni.2020.05.002 Medline

26. J. Braun, L. Loyal, M. Frentsch, D. Wendisch, P. Georg, F. Kurth, S. Hippenstiel, M. Dingeldey, B. Kruse, F. Fauchere, E. Baysal, M. Mangold, L. Henze, R. Lauster, M. A. Mall, K. Beyer, J. Röhmel, S. Voigt, J. Schmitz, S. Miltenyi, I. Demuth, M. A. Müller, A. Hocke, M. Witzenrath, N. Suttorp, F. Kern, U. Reimer, H. Wenschuh, C. Drosten, V. M. Corman, C. Giesecke-Thiel, L. E. Sander, A. Thiel, SARS-CoV-2reactive T cells in healthy donors and patients with COVID-19. Nature 587, 270274 (2020). doi:10.1038/s41586-020-2598-9 Medline

27. A. Grifoni, D. Weiskopf, S. I. Ramirez, J. Mateus, J. M. Dan, C. R. Moderbacher, S. A. Rawlings, A. Sutherland, L. Premkumar, R. S. Jadi, D. Marrama, A. M. de Silva, A. Frazier, A. F. Carlin, J. A. Greenbaum, B. Peters, F. Krammer, D. M. Smith, S. Crotty, A. Sette, Targets of T Cell Responses to SARS-CoV-2 Coronavirus in Humans with COVID-19 Disease and Unexposed Individuals. Cell 181, 14891501.e15 (2020). doi:10.1016/j.cell.2020.05.015 Medline

28. A. Choi, M. Koch, K. Wu, G. Dixon, J. Oestreicher, H. Legault, G. B. E. Stewart-Jones, T. Colpitts, R. Pajon, H. Bennett, A. Carfi, D. K. Edwards, Serum Neutralizing Activity of mRNA-1273 Against SARS-CoV-2 Variants. J. Virol. •.., JVI0131321 (2021). Medline

29. W. F. Garcia-Beltran, E. C. Lam, K. St Denis, A. D. Nitido, Z. H. Garcia, B. M. Hauser, J. Feldman, M. N. Pavlovic, D. J. Gregory, M. C. Poznansky, A. Sigal, A. G. Schmidt, A. J. lafrate, V. Naranbhai, A. B. Balazs, Multiple SARS-CoV-2 variants escape neutralization by vaccine-induced humoral immunity. Cell 184, 2523 (2021). doi:10.1016/i.cell.2021.04.006 Medline

30. J. Liu, Y. Liu, H. Xia, J. Zou, S. C. Weaver, K. A. Swanson, H. Cai, M. Cutler, D. Cooper, A. Muik, K. U. Jansen, U. Sahin, X. Xie, P. R. Dormitzer, P. Y. Shi, BNT162b2-elicited neutralization of B.1.617 and other SARS-CoV-2 variants. 
Nature 596, 273-275 (2021). Medline

31. D. Planas, D. Veyer, A. Baidaliuk, I. Staropoli, F. Guivel-Benhassine, M. M. Rajah, C. Planchais, F. Porrot, N. Robillard, J. Puech, M. Prot, F. Gallais, P. Gantner, A. Velay, J. Le Guen, N. Kassis-Chikhani, D. Edriss, L. Belec, A. Seve, L. Courtellemont, H. Péré, L. Hocqueloux, S. Fafi-Kremer, T. Prazuck, H. Mouquet, T. Bruel, E. SimonLorière, F. A. Rey, O. Schwartz, Reduced sensitivity of SARS-CoV-2 variant Delta to antibody neutralization. Nature 596, 276-280 (2021). doi:10.1038/s41586021-03777-9 Medline

32. T. Tada, B. M. Dcosta, M. I. Samanovic, R. S. Herati, A. Cornelius, H. Zhou, A. Vaill, W. Kazmierski, M. J. Mulligan, N. R. Landau, Convalescent-Phase Sera and Vaccine-Elicited Antibodies Largely Maintain Neutralizing Titer against Global SARS-CoV-2 Variant Spikes. mBio 12, e0069621 (2021). doi:10.1128/mBio.00696-21 Medline

33. K. Wu, A. P. Werner, M. Koch, A. Choi, E. Narayanan, G. B. E. Stewart-Jones, T. Colpitts, H. Bennett, S. Boyoglu-Barnum, W. Shi, J. I. Moliva, N. J. Sullivan, B. S. Graham, A. Carfi, K. S. Corbett, R. A. Seder, D. K. Edwards, Serum Neutralizing Activity Elicited by mRNA-1273 Vaccine. N. Engl. J. Med. 384, 1468-1470 (2021). doi:10.1056/NEJMc2102179 Medline

34. X. Xie, Y. Liu, J. Liu, X. Zhang, J. Zou, C. R. Fontes-Garfias, H. Xia, K. A. Swanson, M. Cutler, D. Cooper, V. D. Menachery, S. C. Weaver, P. R. Dormitzer, P. Y. Shi, Neutralization of SARS-CoV-2 spike 69/70 deletion, E484K and N501Y variants by BNT162b2 vaccine-elicited sera. Nat. Med. 27, 620-621 (2021). doi:10.1038/s41591-021-01270-4 Medline

35. G. Alter, J. Yu, J. Liu, A. Chandrashekar, E. N. Borducchi, L. H. Tostanoski, K. McMahan, C. Jacob-Dolan, D. R. Martinez, A. Chang, T. Anioke, M. Lifton, J. Nkolola, K. E. Stephenson, C. Atyeo, S. Shin, P. Fields, I. Kaplan, H. Robins, F. Amanat, F. Krammer, R. S. Baric, M. Le Gars, J. Sadoff, A. M. de Groot, D. Heerwegh, F. Struyf, M. Douoguih, J. van Hoof, H. Schuitemaker, D. H. Barouch, Immunogenicity of Ad26.COV2.S vaccine against SARS-CoV-2 variants in humans. Nature 596, 268-272 (2021). doi:10.1038/s41586-021-03681-2 Medline

36. T. Tada, H. Zhou, M. I. Samanovic, B. M. Dcosta, A. Cornelius, M. J. Mulligan, N. R. Landau, Comparison of Neutralizing Antibody Titers Elicited by mRNA and Adenoviral Vector Vaccine against SARS-CoV-2 Variants. bioRxiv, 2021.2007.2019.452771 (2021).

37. J. Sadoff, G. Gray, A. Vandebosch, V. Cárdenas, G. Shukarev, B. Grinsztejn, P. A. Goepfert, C. Truyers, H. Fennema, B. Spiessens, K. Offergeld, G. Scheper, K. L. Taylor, M. L. Robb, J. Treanor, D. H. Barouch, J. Stoddard, M. F. Ryser, M. A. Marovich, K. M. Neuzil, L. Corey, N. Cauwenberghs, T. Tanner, K. Hardt, J. RuizGuiñazú, M. Le Gars, H. Schuitemaker, J. Van Hoof, F. Struyf, M. Douoguih; ENSEMBLE Study Group, Safety and Efficacy of Single-Dose Ad26.COV2.S Vaccine against Covid-19. N. Engl. J. Med. 384, 2187-2201 (2021). doi:10.1056/NEJMoa2101544 Medline

38. B. Agerer, M. Koblischke, V. Gudipati, L. F. Montaño-Gutierrez, M. Smyth, A. Popa, J. W. Genger, L. Endler, D. M. Florian, V. Mühlgrabner, M. Graninger, S. W. Aberle, A. M. Husa, L. E. Shaw, A. Lercher, P. Gattinger, R. Torralba-Gombau, D. Trapin, T. Penz, D. Barreca, I. Fae, S. Wenda, M. Traugott, G. Walder, W. F. Pickl, V. Thiel, F. Allerberger, H. Stockinger, E. Puchhammer-Stöckl, W. Weninger, G. Fischer, W. Hoepler, E. Pawelka, A. Zoufaly, R. Valenta, C. Bock, W. Paster, R. Geyeregger, M. Farlik, F. Halbritter, J. B. Huppa, J. H. Aberle, A. Bergthaler, SARS-CoV-2 mutations in MHC-I-restricted epitopes evade $\mathrm{CD}^{+} \mathrm{T}_{\mathrm{T}}$ cell responses. Sci. Immunol. 6, eabg6461 (2021). doi:10.1126/sciimmunol.abg6461 Medline

39. A. Tarke, J. Sidney, N. Methot, E. D. Yu, Y. Zhang, J. M. Dan, B. Goodwin, P. Rubiro, A. Sutherland, E. Wang, A. Frazier, S. I. Ramirez, S. A. Rawlings, D. M. Smith, R. da Silva Antunes, B. Peters, R. H. Scheuermann, D. Weiskopf, S. Crotty, A. Grifoni, A. Sette, Impact of SARS-CoV-2 variants on the total $C D 4^{+}$and $C D 8^{+} T$ cell reactivity in infected or vaccinated individuals. Cell Rep Med 2, 100355 (2021). doi:10.1016/i.xcrm.2021.100355 Medline

40. V. M. Andrade, A. Christensen-Quick, J. Agnes, J. Tur, C. Reed, R. Kalia, I. Marrero, D. Elwood, K. Schultheis, M. Purwar, E. Reuschel, T. McMullan, P. Pezzoli, K Kraynyak, A. Sylvester, M. P. Mammen, P. Tebas, J. J. Kim, D. B. Weiner, T. R. F. Smith, S. J. Ramos, L. M. Humeau, J. D. Boyer, K. E. Broderick, INO-4800 DNA Vaccine Induces Neutralizing Antibodies and T cell Activity Against Global SARSCoV-2 Variants. bioRxiv, 2021.2004.2014.439719 (2021).

41. D. Tsilingiris, N. G. Vallianou, I. Karampela, M. Dalamaga, Vaccine induced thrombotic thrombocytopenia: The shady chapter of a success story. Metabol
Open 11, 100101 (2021). doi:10.1016/i.metop.2021.100101 Medline

42. J. G. Kelton, D. Sheridan, A. Santos, J. Smith, K. Steeves, C. Smith, C. Brown, W. G. Murphy, Heparin-induced thrombocytopenia: Laboratory studies. Blood 72, 925930 (1988). doi:10.1182/blood.V72.3.925.bloodjournal723925 Medline

43. T. Thiele, L. Ulm, S. Holtfreter, L. Schönborn, S. O. Kuhn, C. Scheer, T. E. Warkentin, B. M. Bröker, K. Becker, K. Aurich, K. Selleng, N. O. Hübner, A. Greinacher, Frequency of positive anti-PF4/polyanion antibody tests after COVID-19 vaccination with ChAdOx1 nCoV-19 and BNT162b2. Blood 138, 299-303 (2021). doi:10.1182/blood.2021012217 Medline

44. J. Douxfils, J. Favresse, J. M. Dogné, T. Lecompte, S. Susen, C. Cordonnier, A. Lebreton, R. Gosselin, P. Sié, G. Pernod, Y. Gruel, P. Nguyen, C. Vayne, F. Mullier, Hypotheses behind the very rare cases of thrombosis with thrombocytopenia syndrome after SARS-CoV-2 vaccination. Thromb. Res. 203, 163-171 (2021). doi:10.1016/j,thromres.2021.05.010 Medline

45. A. Greinacher, T. Thiele, T. E. Warkentin, K. Weisser, P. A. Kyrle, S. Eichinger, Thrombotic Thrombocytopenia after ChAd0x1 nCov-19 Vaccination. N. Engl. J. Med. 384, 2092-2101 (2021). doi:10.1056/NEJMoa2104840 Medline

46. M. Othman, A. Labelle, I. Mazzetti, H. S. Elbatarny, D. Lillicrap, Adenovirus-induced thrombocytopenia: The role of von Willebrand factor and P-selectin in mediating accelerated platelet clearance. Blood 109, 2832-2839 (2007). doi:10.1182/blood-2006-06-032524 Medline

47. J. Sadoff, K. Davis, M. Douoguih, Thrombotic Thrombocytopenia after Ad26.COV2.S Vaccination - Response from the Manufacturer. N. Engl. J. Med. 384, 1965-1966 (2021). doi:10.1056/NEJMc2106075 Medline

48. O. Dyer, Covid-19: Countries are learning what others paid for vaccines. BMJ 372 , n281 (2021). Medline

49. S. P. Buchbinder, D. V. Mehrotra, A. Duerr, D. W. Fitzgerald, R. Mogg, D. Li, P. B. Gilbert, J. R. Lama, M. Marmor, C. Del Rio, M. J. McElrath, D. R. Casimiro, K. M. Gottesdiener, J. A. Chodakewitz, L. Corey, M. N. Robertson; Step Study Protocol Team, Efficacy assessment of a cell-mediated immunity HIV-1 vaccine (the Step Study): A double-blind, randomised, placebo-controlled, test-of-concept trial. Lancet 372, 1881-1893 (2008). doi:10.1016/S0140-6736(08)61591-3 Medline

50. S. Zhang, W. Huang, X. Zhou, Q. Zhao, Q. Wang, B. Jia, Seroprevalence of neutralizing antibodies to human adenoviruses type- 5 and type-26 and chimpanzee adenovirus type-68 in healthy Chinese adults. J. Med. Virol. 85, 10771084 (2013). doi:10.1002/imv.23546 Medline

51. T. C. Mast, L. Kierstead, S. B. Gupta, A. A. Nikas, E. G. Kallas, V. Novitsky, B. Mbewe, P. Pitisuttithum, M. Schechter, E. Vardas, N. D. Wolfe, M. Aste-Amezaga, D. R. Casimiro, P. Coplan, W. L. Straus, J. W. Shiver, International epidemiology of human pre-existing adenovirus (Ad) type-5, type-6, type-26 and type-36 neutralizing antibodies: Correlates of high Ad5 titers and implications for potential HIV vaccine trials. Vaccine 28, 950-957 (2010). doi:10.1016/i.vaccine.2009.10.145 Medline

52. K. M. Quinn, A. Da Costa, A. Yamamoto, D. Berry, R. W. Lindsay, P. A. Darrah, L. Wang, C. Cheng, W. P. Kong, J. G. Gall, A. Nicosia, A. Folgori, S. Colloca, R. Cortese, E. Gostick, D. A. Price, C. E. Gomez, M. Esteban, L. S. Wyatt, B. Moss, C. Morgan, M. Roederer, R. T. Bailer, G. J. Nabel, R. A. Koup, R. A. Seder, Comparative analysis of the magnitude, quality, phenotype, and protective capacity of simian immunodeficiency virus gag-specific CD8+ T cells following human-, simian-, and chimpanzee-derived recombinant adenoviral vector immunization. J. Immunol. 190, 2720-2735 (2013). doi:10.4049/iimmunol.1202861 Medline

53. Z. Xiang, Y. Li, A. Cun, W. Yang, S. Ellenberg, W. M. Switzer, M. L. Kalish, H. C. Ertl, Chimpanzee adenovirus antibodies in humans, sub-Saharan Africa. Emerg. Infect. Dis. 12, 1596-1599 (2006). doi:10.3201/eid1210.060078 Medline

54. S. L. Ludwig, J. F. Brundage, P. W. Kelley, R. Nang, C. Towle, D. P. Schnurr, L. Crawford-Miksza, J. C. Gaydos, Prevalence of antibodies to adenovirus serotypes 4 and 7 among unimmunized US Army trainees: Results of a retrospective nationwide seroprevalence survey. J. Infect. Dis. 178, 1776-1778 (1998). doi:10.1086/314498 Medline

55. H. Chen, Z. Q. Xiang, Y. Li, R. K. Kurupati, B. Jia, A. Bian, D. M. Zhou, N. Hutnick, S. Yuan, C. Gray, J. Serwanga, B. Auma, P. Kaleebu, X. Zhou, M. R. Betts, H. C. Ertl, Adenovirus-based vaccines: Comparison of vectors from three species of adenoviridae. J. Virol. 84, 10522-10532 (2010). doi:10.1128/JVI.00450-10 Medline

56. A. R. Thorner, R. Vogels, J. Kaspers, G. J. Weverling, L. Holterman, A. A. Lemckert, 
A. Dilraj, L. M. McNally, P. M. Jeena, S. Jepsen, P. Abbink, A. Nanda, P. E. Swanson, A. T. Bates, K. L. O'Brien, M. J. Havenga, J. Goudsmit, D. H. Barouch, Age dependence of adenovirus-specific neutralizing antibody titers in individuals from sub-Saharan Africa. J. Clin. Microbiol. 44, 3781-3783 (2006). doi:10.1128/JCM.01249-06 Medline

57. E. Zielinska, D. Liu, H. Y. Wu, J. Quiroz, R. Rappaport, D. P. Yang, Development of an improved microneutralization assay for respiratory syncytial virus by automated plaque counting using imaging analysis. Virol. J. 2, 84 (2005). doi:10.1186/1743-422X-2-84 Medline

58. M. Aste-Amézaga, A. J. Bett, F. Wang, D. R. Casimiro, J. M. Antonello, D. K. Patel, E. C. Dell, L. L. Franlin, N. M. Dougherty, P. S. Bennett, H. C. Perry, M. E. Davies, J. W. Shiver, P. M. Keller, M. D. Yeager, Quantitative adenovirus neutralization assays based on the secreted alkaline phosphatase reporter gene: Application in epidemiologic studies and in the design of adenovector vaccines. Hum. Gene Ther. 15, 293-304 (2004). doi:10.1089/104303404322886147 Medline

Acknowledgments: This Phase 1 study was through the participation of clinical trial volunteers. We are profoundly grateful to the volunteers for their effort. We are grateful to the members of the Phase 1 Committee at the National Institute of health (ISS), of the technic-scientific committee of the Italian Drug Regulatory Agency (AIFA) and to the National Ethical Board for COVID-19. We thank the members of the Data Safety and Monitoring Board for the priceless efforts spent for supporting the investigators on assessing information and for advising on trial continuation: Franco Locatelli (President), Paolo Antonio Grossi (Member), Sergio Bonini (Member) and Paolo Bruzzi (Member). We thank Rino Rappuoli for the support for interpretation of the interim analysis results. We finally thank the ReiThera GMP and PD staff. Funding: The phase 1 study has been funded by Regione Lazio and Italian Ministry of research (to AF and EG). INMI authors are supported by the Italian Ministry of Health (Ricerca Corrente line 1, to Gl; COVID2020-12371735, to CA; and COVID-2020-12371817, to MRC). Author contributions: SL, S. Capone, AF, EG and GI conceived and designed the study; AA, SM, EN, RC, FM, CA, CC, S. Capone, VA, MS, MRC and MP oversaw the research activity planning and execution; SL, SM, AA, EN, LS, MMP and ADL managed samples and clinical data collection; A. Sacchi, GM, RG, EC, SB, A. Sommella, AMC, FB performed immunological and virological assays; AR, MG, FG and FN provided study materials and reagents; SL, S. Capone, RC, CA, CC, AV analyzed and interpreted the data; YS, MM, FV, GK, S. Colloca, AF, GI supervised the project; SL, S. Capone and AV wrote the manuscript. All authors critically reviewed the manuscript. Competing interests: S. Capone, RC, FM, VA, FG, FN, MS, SB, A. Sommella, AMC, FB, MG, AR, AV, S. Colloca and AF are employees of ReiThera Srl. AF and S. Colloca are also shareholders of Keires AG. S. Colloca, $A R$, and $A V$ are inventors of the Patent Application No. 20183515.4 titled "GORILLA ADENOVIRUS NUCLEIC ACID- AND AMINO ACID-SEQUENCES, VECTORS CONTAINING SAME, AND USES THEREOF". AA is a paid consultant with honoraria from Gilead, GSK, Merck, Janssen-Cilag, Roche,

Theratecnologies, and ViiV Healthcare. GK was part of the steering committee of the Phase $2 / 3$ study sponsored by ReiThera. All remaining authors declare that they have no competing interests. Data and materials availability: All data are available in the main text or the supplementary materials. This trial is registered with ClinicaTrials.gov, NCT04528641. This work is licensed under a Creative Commons Attribution 4.0 International (CC BY 4.0) license, which permits unrestricted use, distribution, and reproduction in any medium, provided the original work is properly cited. To view a copy of this license, visit https://creativecommons.org/licenses/by/4.0/. This license does not apply to figures/photos/artwork or other content included in the article that is credited to a third party; obtain authorization from the rights holder before using this material.

Submitted 27 April 2021

Accepted 8 October 2021

Published First Release 26 October 2021

10.1126/scitranslmed.abj1996
In addition to the authors listed, the following investigators were part of the GRAd study group:

Sandrine Ottou ${ }^{1}$, Serena Vita ${ }^{1}$, Alessandra Vergori ${ }^{1}$, Alessandra D'Abramo ${ }^{1}$, Antonella Petrecchia ${ }^{1}$, Chiara Montaldo ${ }^{1}$, Emilio Scalise ${ }^{1}$, Germana Grassi' ${ }^{1}$, Rita Casetti14, Veronica Bordoni ${ }^{1}$, Stefania Notari ${ }^{1}$, Francesca Colavita ${ }^{1}$, Silvia Meschii ${ }^{1}$, Daniele Lapa ${ }^{1}$, Licia Bordi ${ }^{1}$, Silvia Murachelli', Teresa Tambasco ${ }^{1}$, Alessandra Grillo', Erminia Masone ${ }^{1}$, Elisa Marchioni ${ }^{1}$, Dorian Bardhi' ${ }^{1}$ Ottavia Porzio ${ }^{14}$, Francesca Cocca ${ }^{14}$, Silvia Murachelli1, Irene Turrini ${ }^{3}$, Feliciana Malescio ${ }^{3}$, Luigi Ziviani ${ }^{3}$, Rita Lawlor ${ }^{3}$, Federica Poli ${ }^{3}$, Federica Martire ${ }^{3}$, Daniela Zamboni ${ }^{3}$, Flavia Mazzaferri ${ }^{3}$.

${ }^{14}$ Ospedale Pediatrico Bambino Gesù (OPBG) - IRCCS, 00165, Rome, Italy 
Fig. 1. Study sample selection and analysis. Enrollment, study population characteristics, treatment and follow-up of the (A) 45 volunteers enrolled in younger age cohort (aged 18 to 55 years), and of the (B) 46 volunteers enrolled in older age cohort (aged 65 to 85 years). Recorded details include age at enrollment in years (median and range) and the body mass index (BMI). A indicates that volunteers were not vaccinated as they were lost in the time window between screening and vaccination visit; ${ }^{B}$ indicates one volunteer excluded from humoral and cellular immunity analysis due SARS-CoV-2 infection immediately before or after vaccination; $\mathrm{C}$ indicates volunteers excluded from ELISpot analysis only, because of high nonspecific IFN-y secretion. ${ }^{D}$ indicates one volunteer excluded from immunogenicity analysis and replaced, due to nonspecific reactivity in an antispike protein CLIA assay.

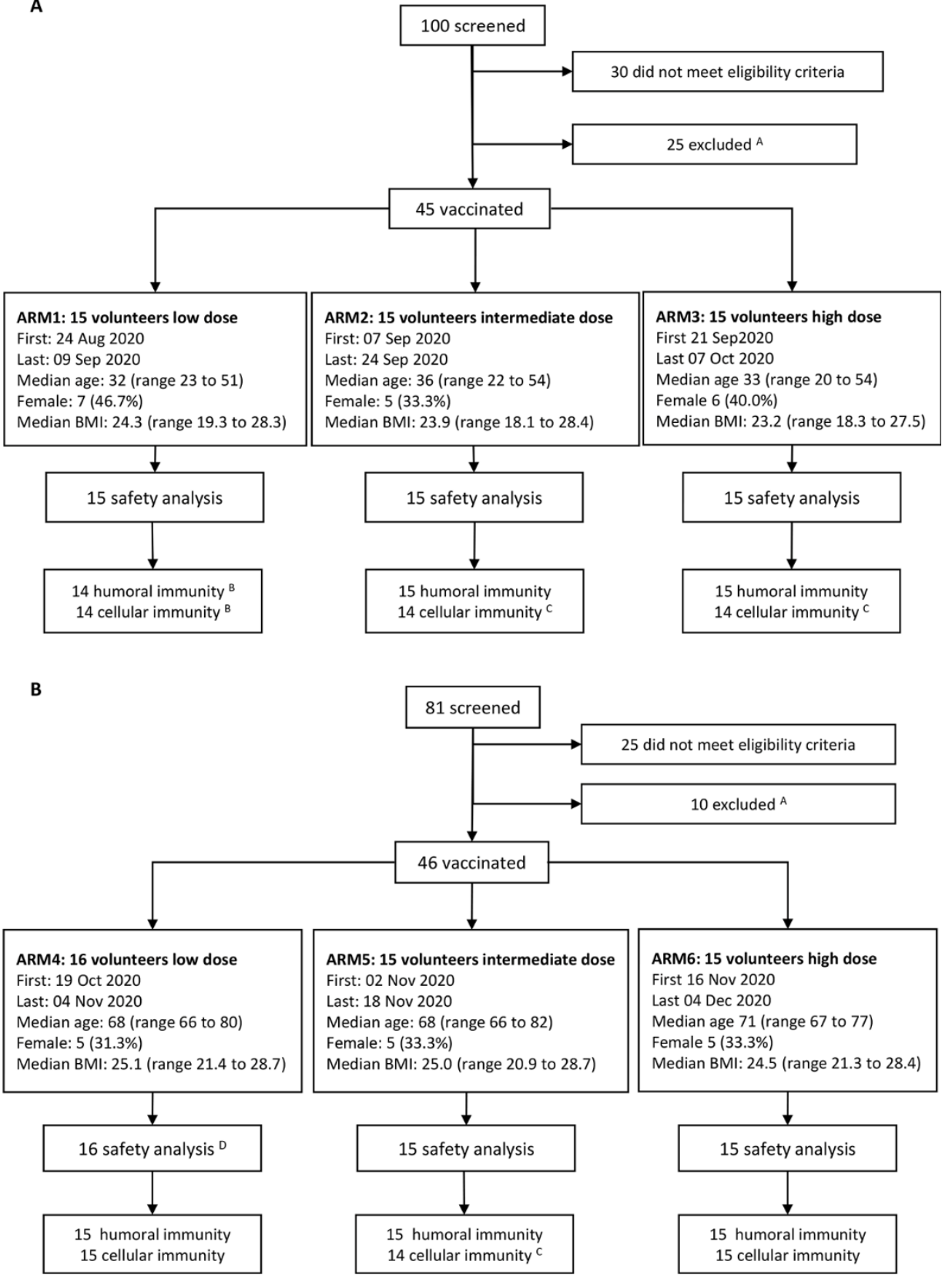




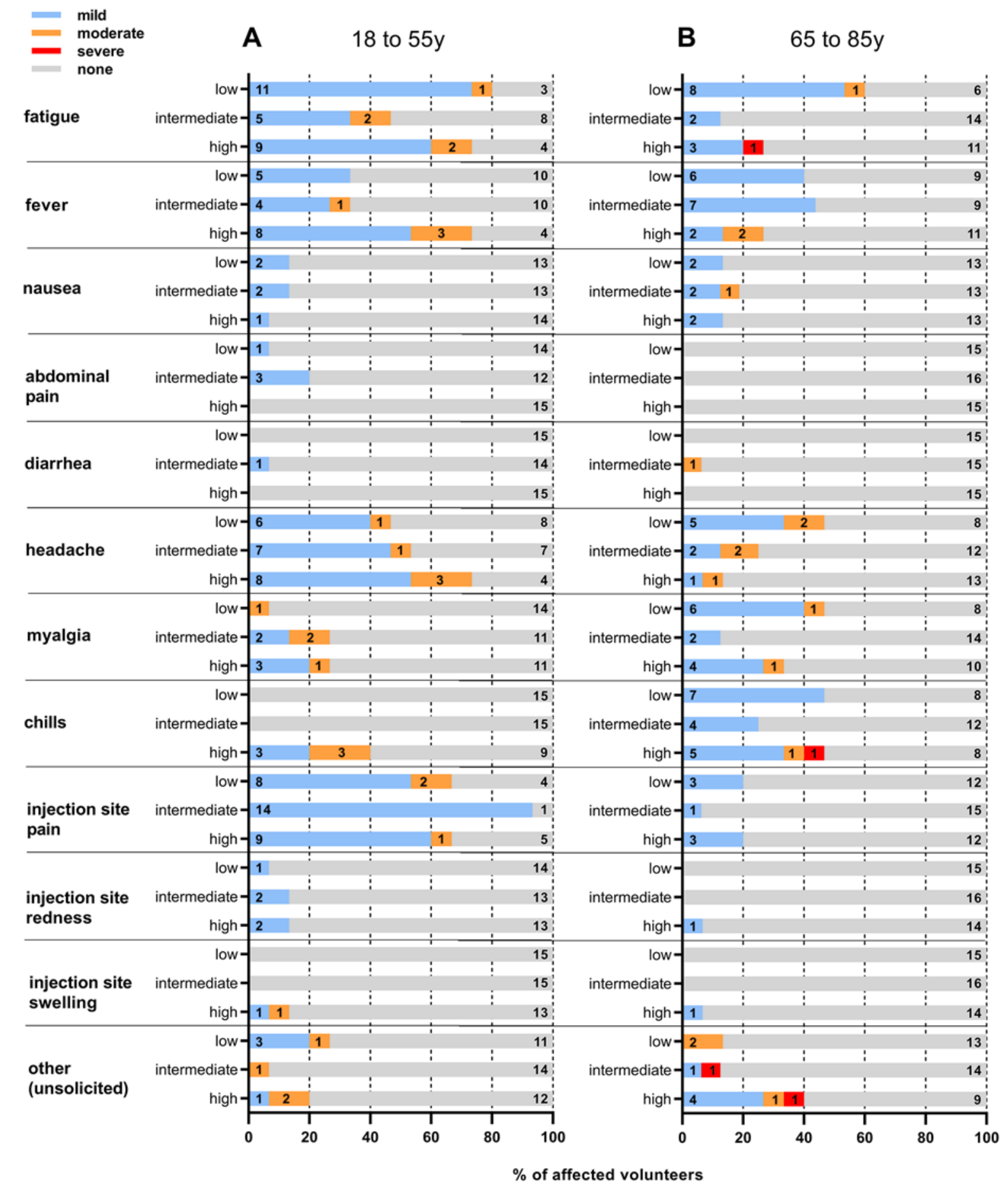

Fig. 2. Adverse Events were recorded within 28 days after vaccination. The proportion of volunteers in each study arm experiencing the specific adverse event (AE), and reported at the maximal severity, is shown. The severity of $A E$ is reported according to intensity scale in the protocol. (A) AEs in the younger adult cohort are shown. (B) AEs in the older adult cohort are shown. Low indicates the low-dose arm $\left(5 \times 10^{10}\right.$ viral particles); intermediate indicates the intermediate-dose arm ( $1 \times 10^{11}$ viral particles); high indicates the highdose arm ( $2 \times 10^{10}$ viral particles). 


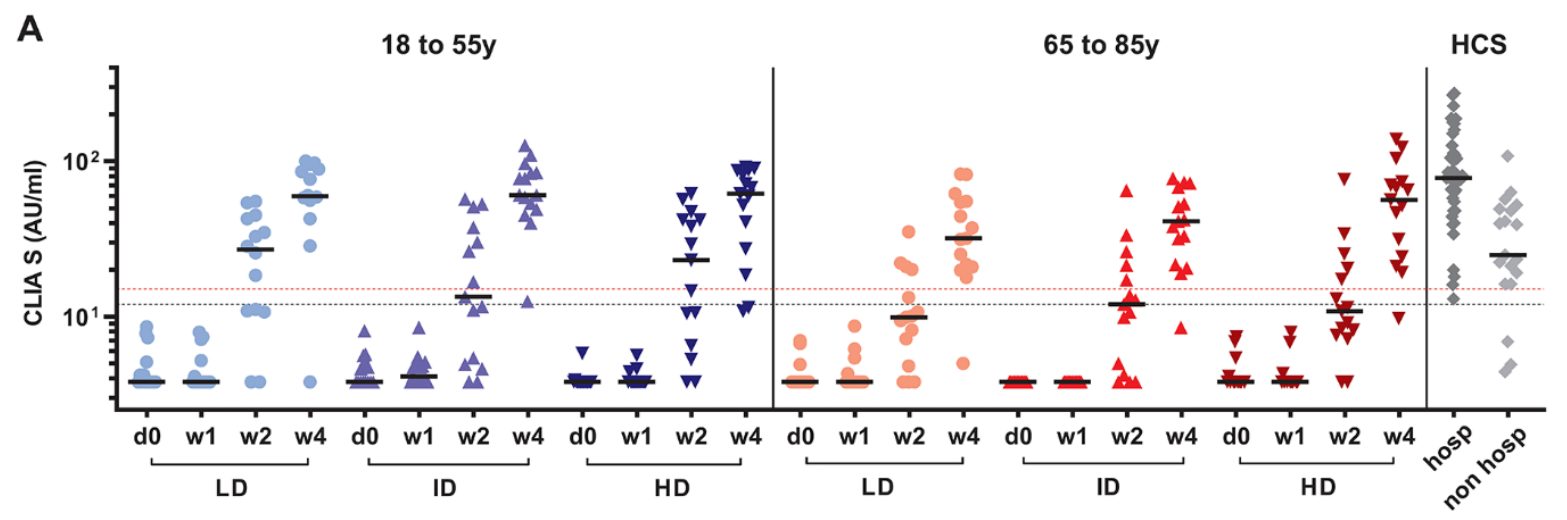

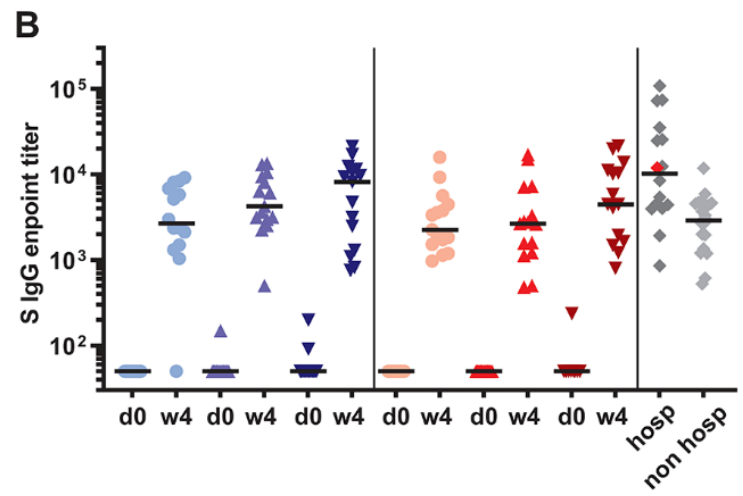

D

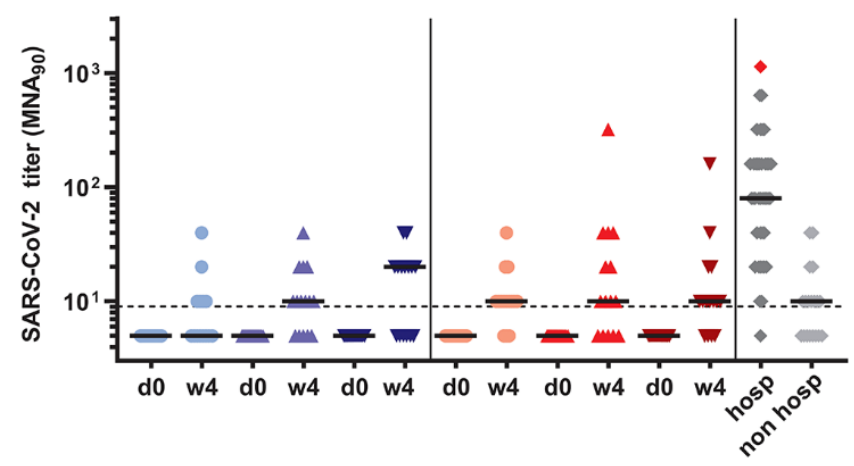

C

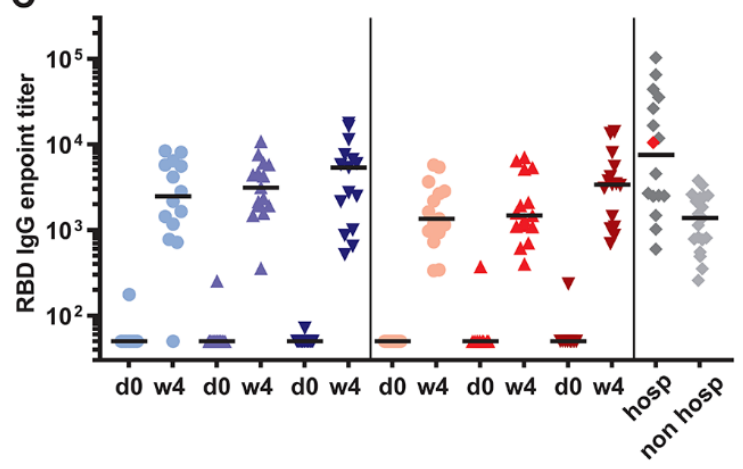

E

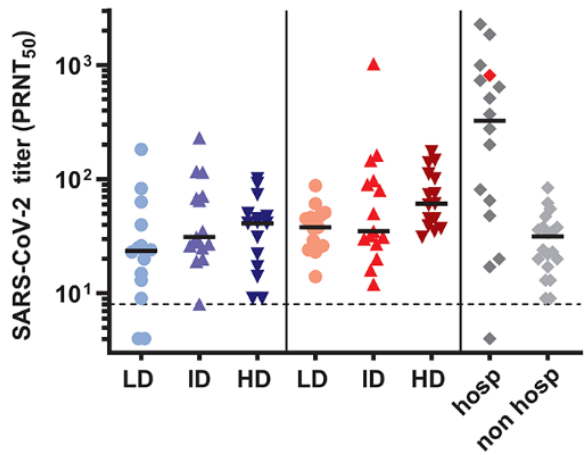

Fig. 3. SARS-CoV-2 specific binding and neutralizing antibody responses were elicited in GRAd-COV2 vaccinated volunteers. Antibody response to SARS-CoV-2 induced by GRAd-COV2 vaccination at low dose (LD, $5 \times 10^{10}$ viral particles; circles), intermediate dose (ID, $1 \times 10^{11}$ viral particles; upright triangles) and high dose (HD, $2 \times 10^{11}$ viral particles; upside down triangles) are shown. (A) IgG binding to S1-S2 was measured by CLIA at day of vaccination ( $\mathrm{dO}$ ), and 1,2 , and 4 weeks after vaccination. Data are expressed as arbitrary unit (AU)/ml. Blue and red dashed lines are set at 12 and $15 \mathrm{AU} / \mathrm{ml}$. According to manufacturer, results greater than 15 are clearly positive, between 12 and 15 are equivocal and below 12 are negative or may indicate low abundance of IgG antibodies to the pathogen. ( $B$ and $C$ ) SARS-CoV-2 specific IgG titers in serum collected at $\mathrm{d} O$ and $w 4$ post vaccination measured by ELISA on recombinant full-length spike protein (B) or RBD (C). Data are expressed as endpoint titer, and for negative serum where a titer cannot be calculated, an arbitrary value of 50 (or one-half of the first serum dilution tested) was assigned. (D and E) SARS-CoV-2 neutralizing antibodies at week 4 post vaccination were detected by SARS-CoV-2 microneutralization assay (D) or by plaque reduction neutralization test (E). SARS-CoV-2 neutralization titers are expressed as $\mathrm{MNA}_{90}$ and $\mathrm{PRNT}_{50}$, or the reciprocal of serum dilution achieving $90 \%$ or $50 \%$ neutralization, respectively. Dashed lines indicate limit of detection (LOD), and negative serum samples were assigned a value of $1 / 2$ the LOD. Blue and red color shades identify younger and older age cohorts, respectively. Horizontal black lines are set at median across all panels. HCS indicates human convalescent serum (diamonds), obtained from either previously hospitalized (hosp-dark gray) or from non-hospitalized (non-hosp-light gray) COVID-19 patients. NIBSC 20/130 standard plasma (red diamond) is shown for reference. 
Fig. 4. SARS-CoV-2 spike protein-specific $T$ cell responses were induced by GRAd-COV2 vaccination. T cell response to spike peptides were induced by GRAd-COV2 vaccination at low (LD, $5 \times 10^{10}$ viral particles; circles), intermediate dose (ID, $1 \times 10^{11}$ viral particles; upright triangles) and

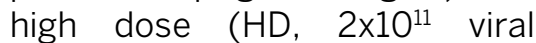
particles; upside down triangles). Blue and red color shades identify younger and older age cohorts, respectively. (A and $B$ ) IFN-Y ELISpots were performed using freshly isolated PBMCs at w2. Data are expressed as IFN-y spot forming cells (SFC) per $10^{6}$ PBMCs. In (A), individual data points represent cumulative spike protein-specific $T$ cell response, calculated by summing the response to each S1a, S1b, S2a and S2b peptide pools stimulation and correcting for background (DMSO stimulation) in each volunteer. HCP indicates freshly isolated human convalescent PBMCs obtained from individuals who recovered from symptomatic SARS-CoV-2 infection. (B) The distribution of IFN-r ELISpot responses to individual spike peptide pools are shown. Dashed line indicates assay positivity cut off (48 SFC per million PBMCs). (C to F) IFN-Y, IL-2, IL-4, and IL17 cytokine production was evaluated at w2 on fresh PBMCs isolated from younger ( $C$ and $D)$ and older volunteers ( $E$ and $F$ ).
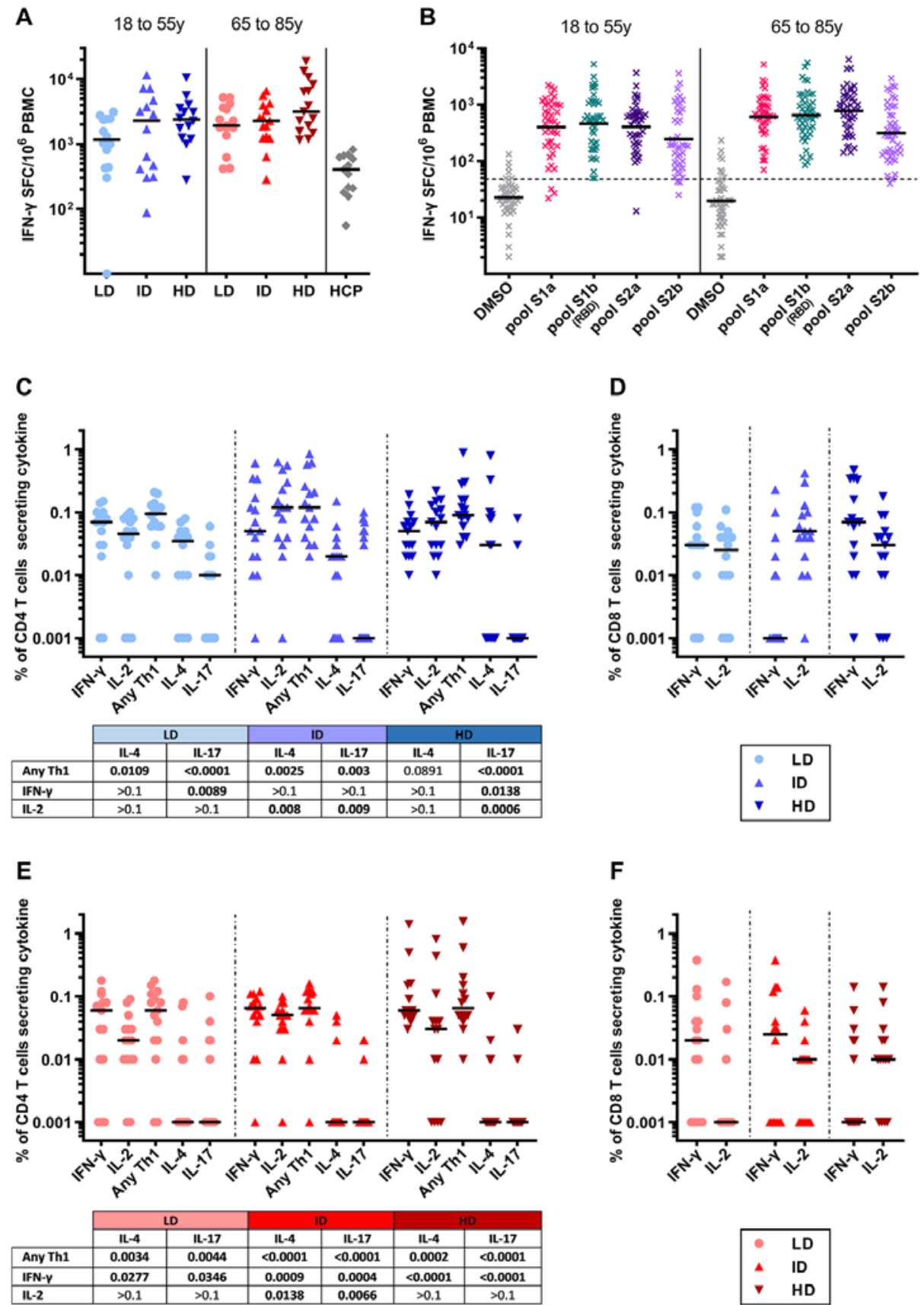

Data are expressed as the percentage of spike protein-specific CD4 T cells ( $C$ and E) or CD8 T cells (D and F) secreting each cytokine. Any Th1 indicates the sum of CD4 secreting IFN- $\gamma$ alone, IL-2 alone, and both IFN- $\gamma$ and IL2), obtained by summing responses to each of the 4 spike peptide pools and corrected for background (DMSO stimulation). The tables below the CD4 T cell plots shows P values derived by Kruskal-Wallis testing comparing Th1, Th2, and Th17 profiles within each dose group. Horizontal black lines are set at median across all panels. 

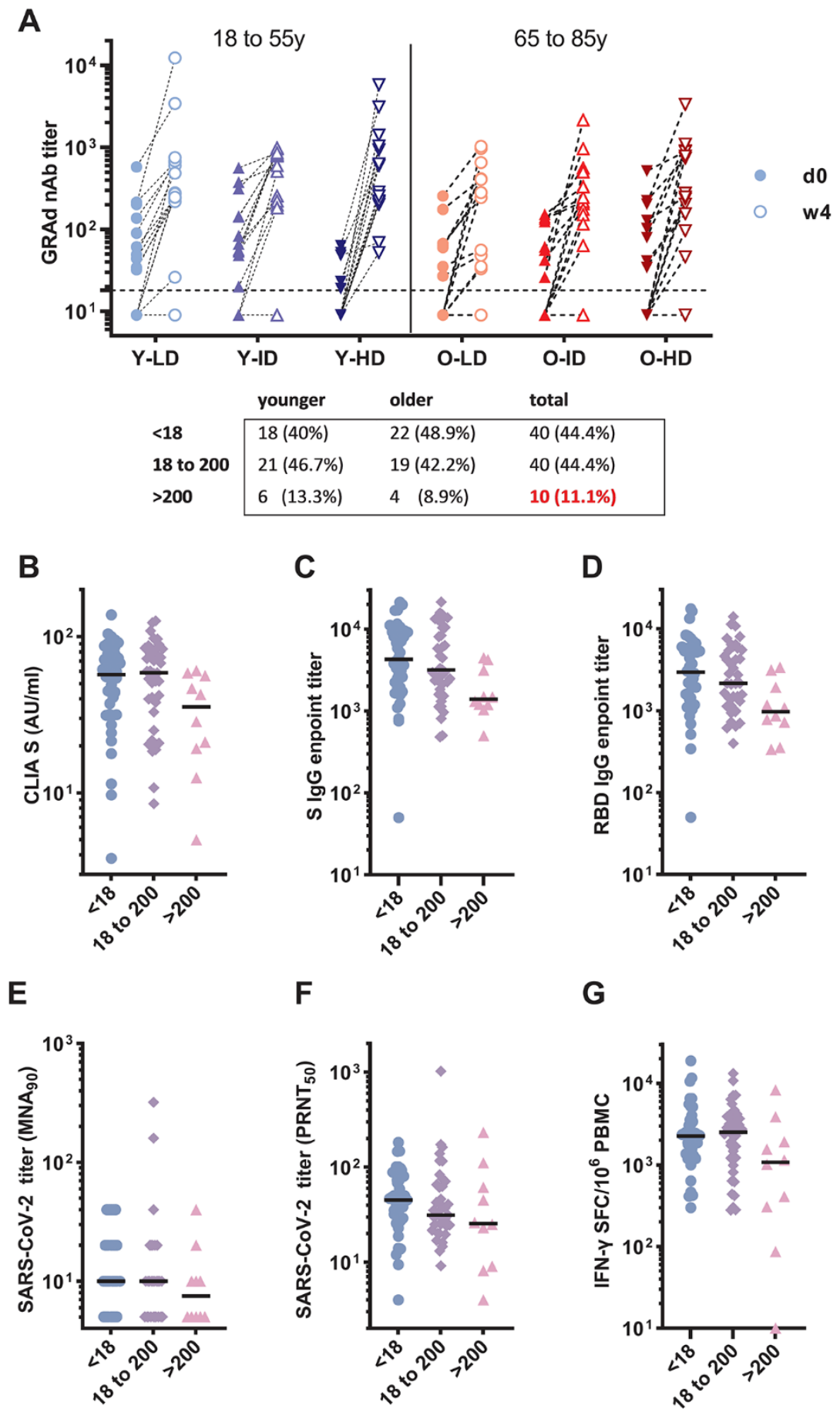

$\mathbf{F}$

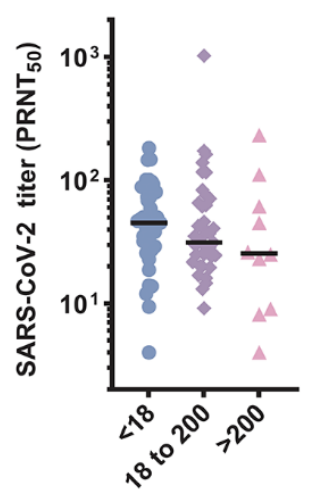

G

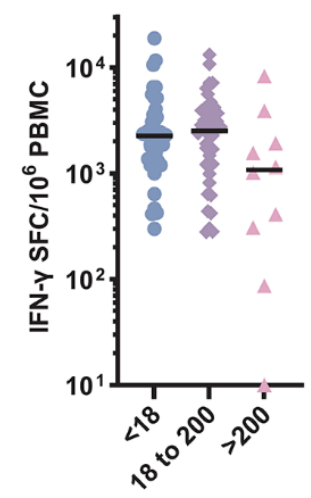

Fig. 5. Neutralizing titers against GRAd were observed in a subset of individuals before and after vaccination. (A) Neutralizing titers to the GRAd vector measured in serum from vaccinated volunteers the day of vaccination (d0, filled symbols) and 4 weeks after (w4, open symbols). The dashed lines set at 18 indicate the assay LOD. The table reports the number (and percentage) of serum samples with GRAd nAb titer in the indicated range $(<18,18$ to 200 or $>200)$ in younger, or older individuals and overall across the two age cohorts of volunteers $(N=90)$. (B to $D)$ Participants were stratified according their GRAd nAb serostatus at baseline, irrespective of age cohort and vaccine dose received, and for each stratum, the antibody response is shown at w4 by CLIA for spike protein-specific IgG (B), by ELISA for spike protein-specific antibodies, (C), by ELISA for RBD-specific antibodies (D). (E and F) the SARS-CoV-2 neutralizing antibody response is shown stratified by GRAd antibody serostatus at w4 by MNA $A_{90}(E)$ and PRNT $50(F)$. (G) The T cell response is shown stratified by GRAd antibody serostatus at w2 by IFN- $\curlyvee$ ELISpot. Horizontal black lines are set at median (B to $G$ ). 
A

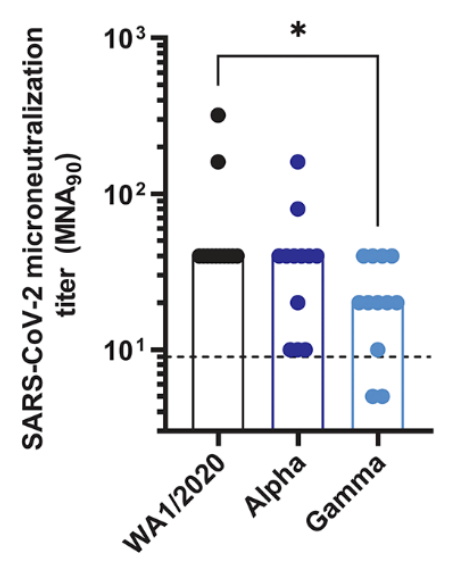

B

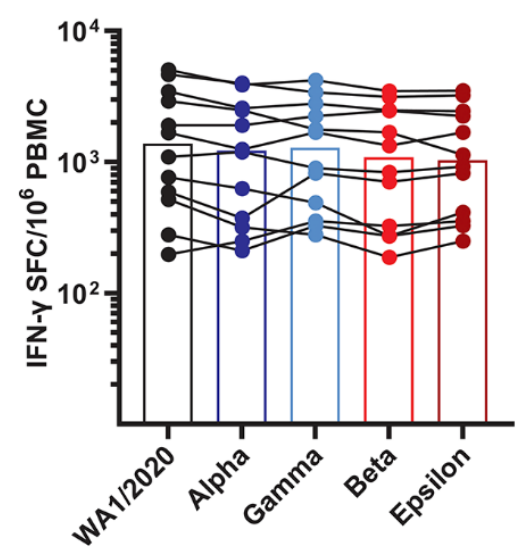

Fig. 6. GRAd-CoV2 elicits immune responses that react to SARS-CoV-2 VOCs. (A) Serum samples from 12 volunteers across all study arms 4 weeks after vaccination were analyzed by MNA assay with the reference strain (WA/2020) or the alpha or the gamma variant strains. SARS-CoV-2 neutralization titers are expressed as $M_{N A}$. Dashed line indicates LOD, and negative sera are assigned a value of one-half of the LOD. (B) IFN- $\curlyvee$ ELISpot was conducted using frozen PBMC with peptide pools covering the full-length spike protein from the prototype WA1/2020, and the alpha, gamma, beta and epsilon variant strains. Data are expressed as IFN- $\gamma$ spot forming cells (SFC) $/ 10^{6}$ PBMCs. Data points represent cumulative spike protein-specific $\mathrm{T}$ cell responses in PBMCs isolated from each individual, summing the response to S1 and S2 peptide pools of each strain and correcting for background (DMSO). Bars in (A) and (B) are set at median. Statistical analysis was done using Friedman's test with Dunn's correction for multiple comparisons (A and B). 